\title{
Magnetic Resonance Imaging of Myocardial Deformation and Scarring in Coronary Artery Disease
}

\author{
Johan Kihlberg
}

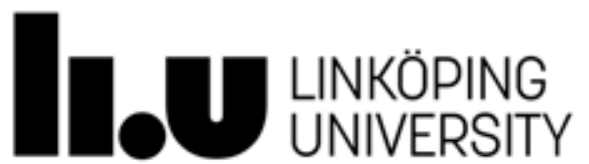

Center for Medical Image Science and Visualization (CMIV)

Division of Radiological Sciences

Department of Medical and Health Sciences

Faculty of Medicine and Health Sciences

Linköping University, Sweden

Linköping 2017 
(๖Johan Kihlberg, 2017

Cover: Short axis view of the heart with circumferential strain as an overlay of infarcted myocardium. Visualization by Vikas Gupta.

This work was conducted in collaboration with the Center for Medical Image Science and Visualization (CMIV) at Linköping University, Sweden. CMIV is acknowledged for the provision of financial support and access to leading-edge research infrastructure.

Published articles have been reprinted with the permission of the copyright holder.

Printed in Sweden by LiU-Tryck, Linköping, Sweden, 2017

ISBN 978-91-7685-431-0

ISSN $0345-0082$ 
To my beloved wife Annika, and to my children

Emelie, Samuel, Sofia, and Linnéa.

...of making many books there is no end; and much study is a weariness of the flesh.

Ecclesiastes 12:12 KJV 



\section{CONTENTS}

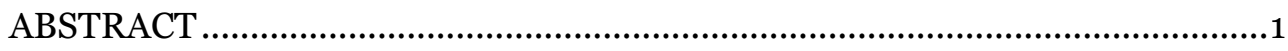

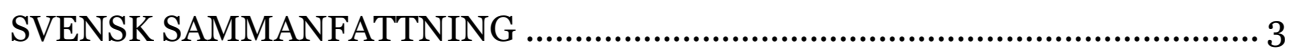

LIST OF PAPERS …………………................................................................ 5

ABBREVIATIONS..................................................................................... 7

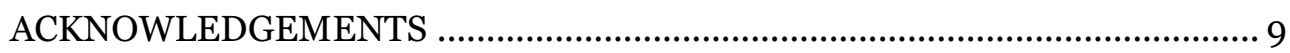

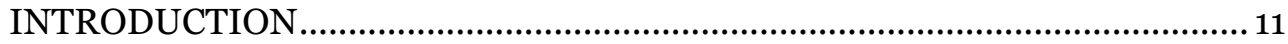

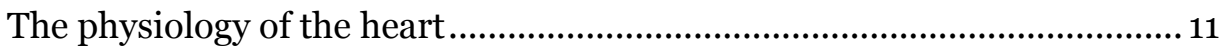

Myocardial infarction and heart failure .........................................................14

Magnetic resonance imaging ......................................................................16

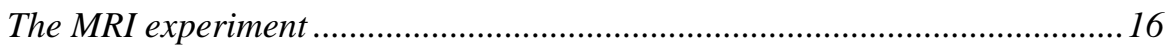

The MRI pulse sequence ............................................................................... 17

The spin echo sequence ................................................................................. 18

The gradient echo sequence ………………………………........................... 19

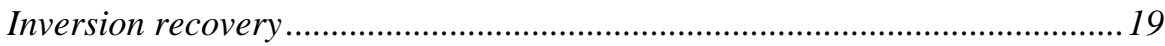

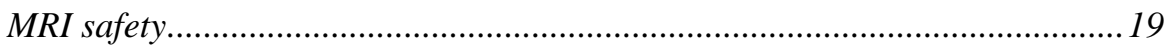

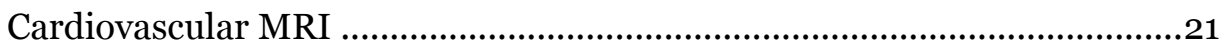

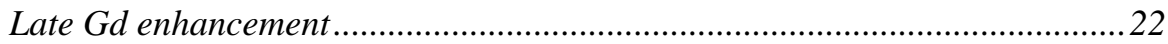

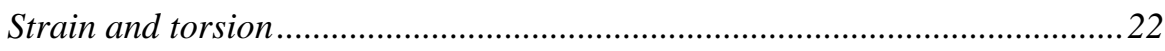

MRI from the patient perspective................................................................... 27

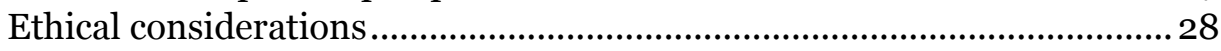

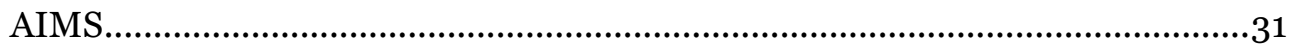

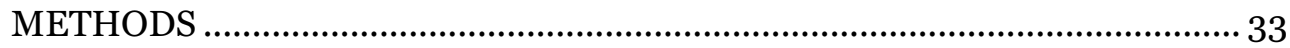

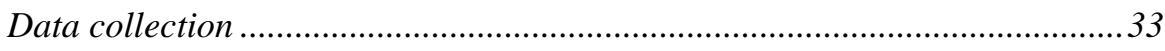

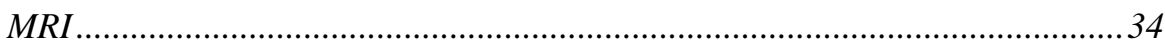

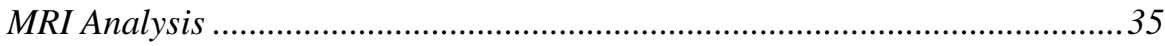

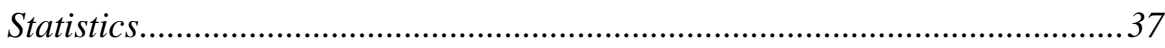

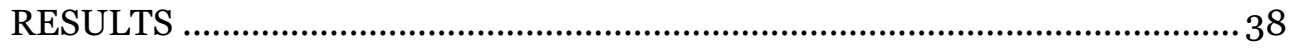

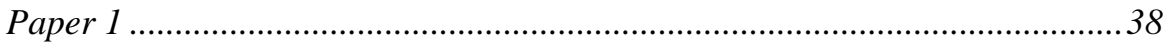

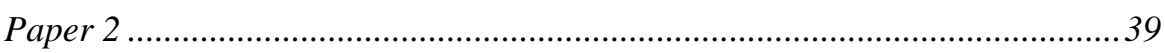




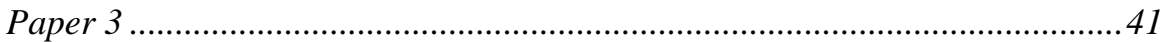

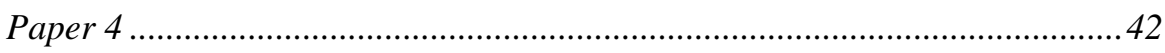

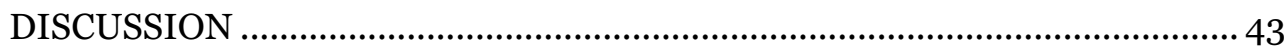

Aspects of the results..................................................................... 43

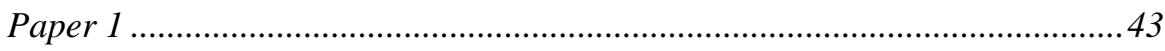

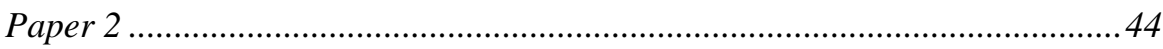

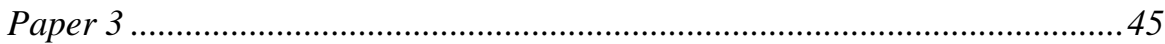

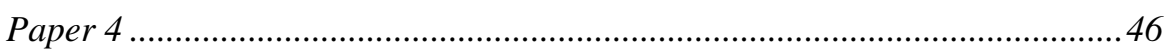

Methodological considerations .......................................................... 47

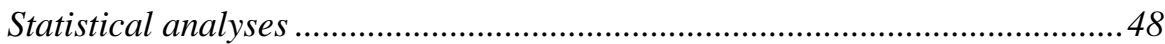

General discussion ................................................................................ 48

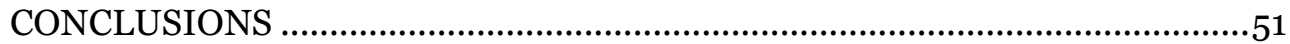

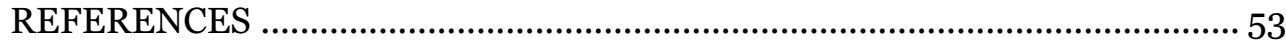




\section{ABSTRACT}

Although improved treatments have reduced the rates of acute complications from myocardial infarction, sequelae such as heart failure and sudden death threaten the future wellbeing of those patients. Secondary prevention after myocardial infarction is related to cardiovascular risk factors and the effect of the infarct on left ventricular function. Cardiovascular magnetic resonance imaging (CMR) is necessary to determine the size of the infarct scar and can with great precision determine left ventricular volumes, left ventricular ejection fraction, and deformation (strain and torsion). The purpose of this thesis was to improve on CMR methods to facilitate image acquisition and post processing in patients with high risk of coronary artery disease (CAD).

In Paper 1, a three-dimensional phase-sensitive inversion-recovery $(3 \mathrm{D}$ PSIR) sequence was modified to measure T1 during a single breath hold. The measured $\mathrm{T} 1$ values were used to extrapolate a map of T1 relaxation, which avoided the time-consuming manual determination of the inversion time. The data collection consisted of phantom experiments, Monte Carlo simulations of the effect of various heart rates, and clinical investigation of 18 patients with myocardial infarction. Scar images created with the modified sequence were compared to those created with the standard sequence. The $3 \mathrm{D}$ PSIR sequence was able to measure T1 relaxation with a high accuracy up to $800 \mathrm{~ms}$, which is in the suitable range for scar imaging. Simulated arrhythmias showed that the method was robust and able to tolerate some variation in heart rate. The modified sequence provides measurements of inversion time that can be used to facilitate standard scar imaging or to reconstruct synthetic scar images. Images of infarct scar obtained with the 3D PSIR sequence bore striking similarity to images obtained with the standard sequence.

In Paper 2, 125 patients with high risk of CAD were investigated using the displacement encoding with stimulated echoes (DENSE) sequence. Image segments with infarct scar area $>50 \%$ (transmurality) could be identified with a sensitivity of $95 \%$ and a specificity of $80 \%$ based on circumferential strain calculated from the DENSE measurements. The DENSE sequence was also applied in other directions, but its sensitivity and specificity to detect scar was lower than when used for circumferential strain.

In Paper 3, 90 patients with high risk of CAD were examined by DENSE, tagging with harmonic phase (HARP) imaging and cine imaging with feature tracking (FT), to detect cardiac abnormalities as manifested in endsystolic circumferential strain. Circumferential strain calculated with 
DENSE had higher sensitivity and specificity than the competing methods to detect infarction with transmurality $>50 \%$. Global circumferential strain measured by DENSE correlated better with global parameters such as left ventricular ejection fraction, myocardial wall mass, left ventricular end-diastolic and end-systolic volume; than strain measured by FT or HARP.

In Paper 4, myocardial torsion was investigated using DENSE, HARP, and FT in 48 patients with high risk of CAD. Torsion measured by each of the three methods was correlated with other global measures such as left ventricular ejection fraction, left ventricular mass, and left ventricular enddiastolic and end-systolic volumes. The torsion measurements obtained with DENSE had a stronger relationship with left ventricular ejection fraction, left ventricular mass, and volumes than those obtained with HARP or FT.

DENSE was superior to the other methods for strain and torsion measurement and can be used to describe myocardial deformation quantitatively and objectively. 


\section{SVENSK SAMMANFATTNING}

Nästan 25700 svenskar insjuknar i hjärtinfarkt per år. Flertalet tillfrisknar men infarkten kan leda till komplikationer t.ex. utveckling av hjärtsvikt. Eftervården av hjärtinfarkt styrs av patientens riskfaktorer och av infarktens storlek. Med en magnetkameraundersökning kan storleken av hjärtinfarkten bestämmas med hög noggrannhet och en bedömning av hjärtats väggrörlighet göras, i alla dess plan och oberoende av hjärtats storlek. Det finns vissa svårigheter vid magnetkameraundersökningar av hjärtat, dels bestämning av inversionstiden hos patienter som undersöks med kontrastmedel och dels bedömning av hjärtrörligheten vilken är kvalitativ och subjektiv. Syftet med avhandlingen var att kvantifiera bildinsamling och efterbearbetning så att undersökning och diagnostik underlättas.

I det första arbetet modifierades en 3D PSIR sekvens så att efterbearbetningen kunde kvantifiera T1 -relaxationen i hjärtmuskeln. Först testades sekvensen i vätskefyllda modeller med känd T1 relaxation och sedan simulerades utfallet av undersökningen vid olika hjärtfrekvenser för att se hjärtfrekvensens påverkan på mätningen. Till slut testades sekvensen och syntetiska bilder på 18 patienter med hjärtinfarkt. Det visade sig att metoden kunde mäta $\mathrm{T} 1$ relaxationen med en hög noggrannhet upp till 8ooms. Simuleringarna av arytmi visade att metoden var robust och de framtagna syntetiska bilderna visade god överenstämmelse jämfört med en standardsekvens. Detta ger möjlighet att på ett kvantitativt sätt mäta relaxationen efter kontrastinjektion och därmed både fastställa en korrekt inversionstid för infarktvisualisering, men också framställa syntetiska infarkt-bilder enbart baserat på relaxationsdata.

Syftet med delarbete två var att med strain detektera hjärtinfarkt och bestämma metodens sensitivitet och specificitet. 125 patienter med hög risk för kranskärlssjuka undersöktes med sekvensen DENSE. Cirkumferentiell strain kunde detektera en infarktstorlek på $>50 \%$ av hjärtsegmentets yta med sensitivitet $95 \%$ och specificitet $80 \%$. Cirkumferentiell strain hade högst sensitivitet och specificitet följd av longitudinell och därefter radiell strain.

I delarbete tre var syftet att jämföra strain från DENSE med två andra strain-mätningar med magnetkamera, den ena med hjälp av tagging med HARP och den andra med cine bilder och metoden feature tracking (FT). Patientgruppen hade hög risk för kranskärlssjuka. 90 patienter undersöktes med cirkumferentiell strain i slutsystolisk pumpfas beräknad med alla tre metoderna. Det visade sig att strain från DENSE kunde detektera en 
infarktskada som var större än 50\% med högre sensitivitet och specificitet än de övriga metoderna. Global cirkumferentiell strain från DENSE korrelerade bättre med globala mått såsom total infarktvolym, ejektionsfraktion och kammarvolymer än vad strain från FT och HARP kunde visa.

I det fjärde delarbetet undersöktes hjärtats torsion med hjälp av tre olika magnetkamerametoder, DENSE, tagging med HARP och cine med FT. 48 patienter inkluderades med stor risk för kranskärlssjukdom och jämfördes med globala mått såsom ejektionsfraktion, kammarmassa, slutsystolisk och slutdiastolisk volym. Ett starkare samband påvisades mellan DENSE torsion och ejektionsfraktion, kammarmassa, slutsystolisk och slutdiastolisk volym än mellan dessa och torsion från HARP respektive FT.

Strain och torsion från DENSE kan sannolikt inte ersätta infarktavbildning med kontrastmedel, men kan användas för att beskriva hjärtats väggrörlighet kvantitativt och objektivt både vid infarktskada och vid andra sjukdomstillstånd där hjärtat drabbas tex högt blodtryck, hjärtsvikt och övervikt. 


\section{LIST OF PAPERS}

I. Warntjes M, Kihlberg J, Engvall J. Rapid T1 quantification based on $3 D$ phase sensitive inversion recovery. BMC Med Imaging 2010;10:19.

II. Kihlberg J, Haraldsson H, Sigfridsson A, Ebbers T, Engvall JE. Clinical experience of strain imaging using DENSE for detecting infarcted cardiac segments. J Cardiovasc Magn Reson 2015;17:1-9.

III. Kihlberg J, Gupta V, Haraldsson H, Sigfridsson A, Sarvari SI, Ebbers T, Engvall JE. Magnetic Resonance Imaging with DENSE Outperforms Feature Tracking and Tagging for Assessment of Myocardial Strain. Manuscript

IV. Kihlberg J, Gupta V, Haraldsson H, Sigfridsson A, Sarvari SI, Ebbers T, Engvall JE Left ventricular mass, function and volume correlate better with torsion determined with DENSE than with magnetic resonance tagging and feature tracking. Manuscript 
Magnetic Resonance Imaging of Myocardial Deformation and Scarring in Coronary Artery Disease. 


\section{ABBREVIATIONS}

3D PSIR Three-Dimensional Phase Sensitive Inversion Recovery

ATP Adenosine Triphosphate

AUC Area Under the Curve

CAD Coronary Artery Disease

CMR Cardiac Magnetic Resonance

CSPAMM Complementary Spatial Modulation of Magnetization

DENSE Displacement Encoding with Stimulated Echoes

ECG Electrocardiography

ECV Extra Cellular Volume

ED End Diastole

EPI Echo Planar Imaging

ES End Systole

FT Feature Tracking

GCS Global Circumferential Strain

Gd Gadolinium

GFR Glomerular Filtration Rate

GLS Global Longitudinal Strain

HARP Harmonic Phase Imaging

ICC Intra-class Correlation Coefficient

IR-TFE Inversion Recovery Turbo Field Echo 
LGE Late Gadolinium Enhancement

LVEDV Left Ventricular End Diastolic Volume

LVEF Left Ventricular Ejection Fraction

LVESV Left Ventricular End Systolic Volume

LVM Left Ventricular Wall Mass

MRI Magnetic Resonance Imaging

PSIR Phase Sensitive Inversion Recovery

RF Radio Frequency

ROC Receiver-Operator Characteristic

ROI Region of Interest

SA Short Axis

SD Standard Deviation

SSFP Steady State Free Precession

TE Echo Time

TFEPI Turbo Field Echo Planar Imaging

TI Inversion Time

TR Repetition Time 


\section{ACKNOWLEDGEMENTS}

There are many people I want to thank that made this journey possible. There have been periods of long days, tricky tasks and difficulties, but it all fades away thanks to the gratification of learning new things, to being able to immerse myself in my research and in the cohabitation of amazing colleagues and friends. I would especially like to thank:

All participating patients for your time!

Jan Engvall, my main supervisor, who, with tireless enthusiasm and imagination, constantly believed in me. Thank you for all your support no matter what time of day or what part of the world you were in!

Tino Ebbers, my co-supervisor, for your cleverness and sharpness. Thank you for your ever-sincere support and friendship. You're a real scientist!

Anders Persson, my co-supervisor, for your incredibly positive attitude to everything! It inspires and impresses not only in my research work but in my daily work environment! You are a true visionary!

My co-authors Marcel Warntjes, Henrik Haraldsson Andreas Lambert (former Sigfridsson) and Vikas Gupta for your willingness to share your knowledge of MRI physics, mechanics and programming. Thanks for coding, not only once but many times! I've learned things I did not have a clue about!

Gunborg Gidby for logistics work around Doppler-CIP and Andreas Bussman, Ingela Eriksson and Annika Hall for all the help with data collection in Mr-STEMI and Doppler-CIP. You have done an incredible job!

Henrik Ekman for your loyalty to me! You are a real friend! And to Christer Holm, Marcelo Martin, Emelie Blomqvist, Miroslav Straleger, Tessan Widén, Charlotte Lundström, Mona Cederholm and Carina Johansson for all your help in our daily work! You've really made it possible to relieve me, and I'm so grateful that you've done it with joy.

Maria Kvist, for you really are the "cement" in CMIV. Your social ability not only affects me, but makes the whole work in CMIV enjoyable! Thank you also Marie Waltersson, Dennis Carlsson, Suzanne Witt and Catrin Nejdeby for getting the research school, data infrastructure, fMRI-studies and the economy to work! 
All of you who showed the way, I really revere you, especially Carina Stenman and Britt-Marie Ahlander. It's just for me to follow you! For me, Anders Tissel, Olof Dahlqvist-Leinhard, Mikael Forsgren and Nils Dahlström are heroes. Thank you for all the inspirational conversations!

The entire CMR research group, but especially Carl-Johan Carlhäll, Sofia Kvernby, Petter Dyverfeldt and Federica Viola for your help and support! And thanks to all at CMIV's Research School for all interesting and rewarding presentations and discussions! And thanks to Bharti Kataria, Liselott Lundvall and Lilian Henriksson for sharing the interest in radiography and research.

My friends, who helped me see what's most important in life!

My mother Ulla, for all support through life! And thanks to my brother Ola and sister Maria with families for you have always been there for me!

My dear children Emelie, Samuel, Sofia and Linnéa. You've given me so much and I've learned so much from you! Thank you for letting me take the time to do this work!

My beloved wife Annika, mother of my children and a precious friend. Thank you for being my wife for 25 years and thank you for your constant love and support in all phases of life. I love you. 


\section{INTRODUCTION}

\section{The physiology of the heart}

The heart pumps blood, with oxygen and nutrients, to all parts of the body. Deoxygenated blood is pumped from the right ventricle via the pulmonary arteries to the alveoli of the lungs, where it is oxygenated and carbon dioxide is expelled (Figure 1). The blood returns to the heart through the pulmonary veins and enters the left atrium. The blood fills the left ventricle (LV) as a result of a combination of sucking caused by the elastic recoil of the LV heart muscle (myocardium) and active pumping by the left atrium. From the LV, the blood is ejected into the systemic circulation via the aortic valve. When the blood reaches the peripheral capillary bed, oxygen is released to the tissues and carbon dioxide is taken up. From the capillaries, the blood is carried via the vena cava and the right atrium and ventricle to the lungs for renewed processing. Variation in intrathoracic pressure due to respiration is the main mechanism driving blood to enter the right ventricle. Temporal variation in intracardiac pressure differences govern the opening of the valves between the atria and the ventricles (Figure 2).

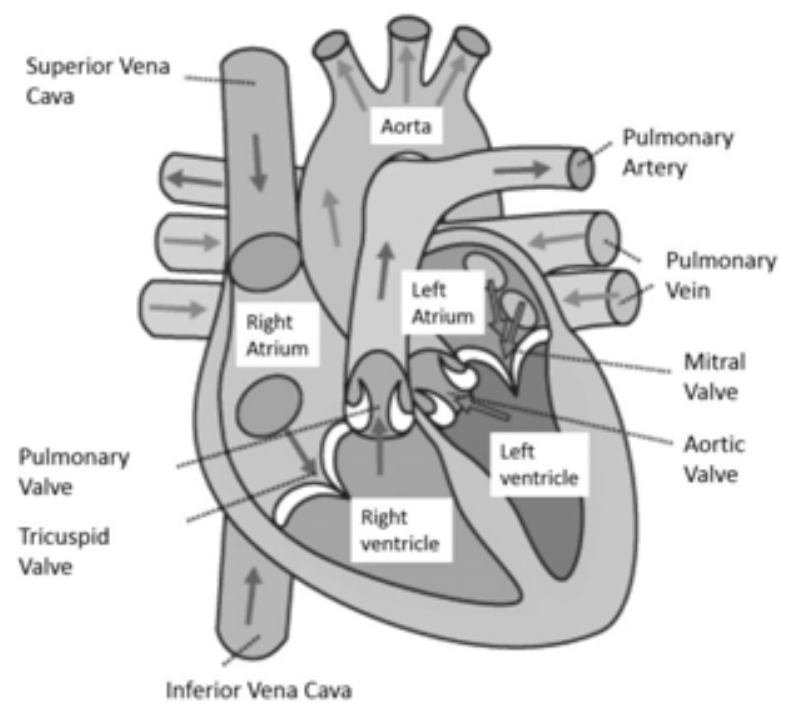

Figure 1. Schematic view of the cardiac flow pattern.

Late in the diastolic phase, the atria contract, and additional filling of the ventricles occurs. The valves close in response to slight pressure differences. The aortic and pulmonary valves open when the pressure in the chambers exceeds the pressure in the great arteries. Over time, the same 
volume of blood is pumped into the systemic circulation as into the pulmonary system, although there can be short-lived minor differences. Because systolic pressure is higher in the systemic circulation than in the pulmonary circulation, the systemic afterload (resistance to blood flow) is much higher than the pulmonary afterload. To compensate for the higher afterload, the myocardium of the LV is thicker (concentric hypertrophy if exaggerated by hypertension) than that of the right ventricle.

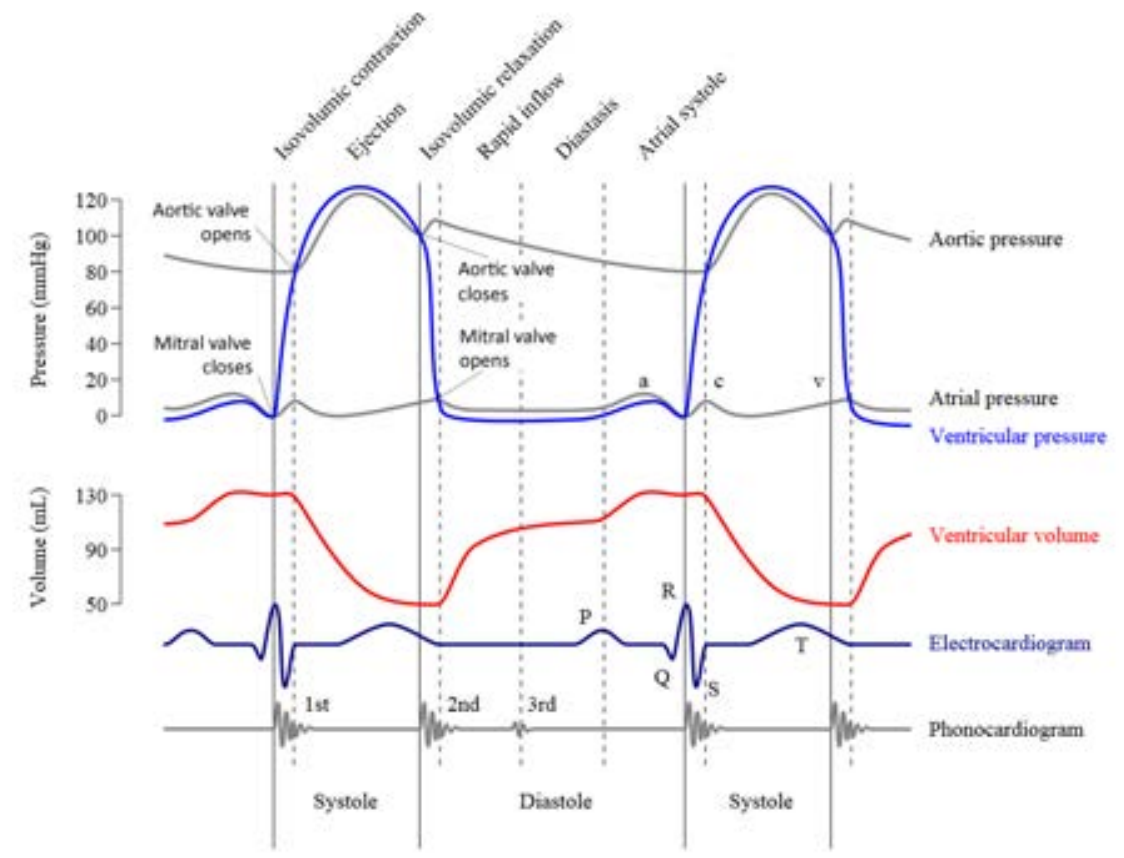

Figure 2. Temporal variation in LV volume and intracardiac pressures related to electrocardiogram and recorded heart sounds according to Carl Wiggers.

Three main factors are associated with pumping performance: first, the afterload, or resistance of the system into which the heart is pumping; second, the contractility, or force-generating capability of the myocardium; and third, the pre-load, or end-diastolic volume immediately before contraction. According to the theory put forward by Frank and Starling, myocardial contraction develops greater force when the cardiac muscle fibers are stretched as a normal response to an increase in pre-load. The contractility depends on a combination of factors including, for example, stimulation from autonomic cardiac innervation, the intrinsic state of the cardiac muscle, and the effects of humoral stimulation. The afterload (expressed in terms of "impedance" in fluid mechanics) depends on the peripheral resistance, which is increased in hypertension; the stiffness of the walls of the great arteries also contributes to the afterload.

In healthy subjects, the differences between end-systolic and end-diastolic volumes can be more than $70 \%$, but the total cardiac volume, including 
the heart muscle and all of the cavities of the heart, changes little between systole and diastole, $8 \%$ on average. That means that contraction of the ventricles is complex [1].

The myocardial muscle cell (myocyte) contains the proteins actin and myosin, which contract in the presence of calcium. The electrical depolarization of the cell membrane releases calcium ions, causing contraction, which spreads via cell-to-cell contacts according to the distribution of the conduction system of the heart. The myocardium of the LV is often described in simplified terms as consisting of three layers: the subendocardial layer with longitudinal fiber direction, the mid-wall layer with circular fibers, and the epicardial layer with mainly longitudinal fiber direction [2-4].

The myocardial cells are oriented and clustered into fibers and bundles that can be regarded as a continuous loop twisted around the heart, what has been called "the apical loop" (see Figure 3).
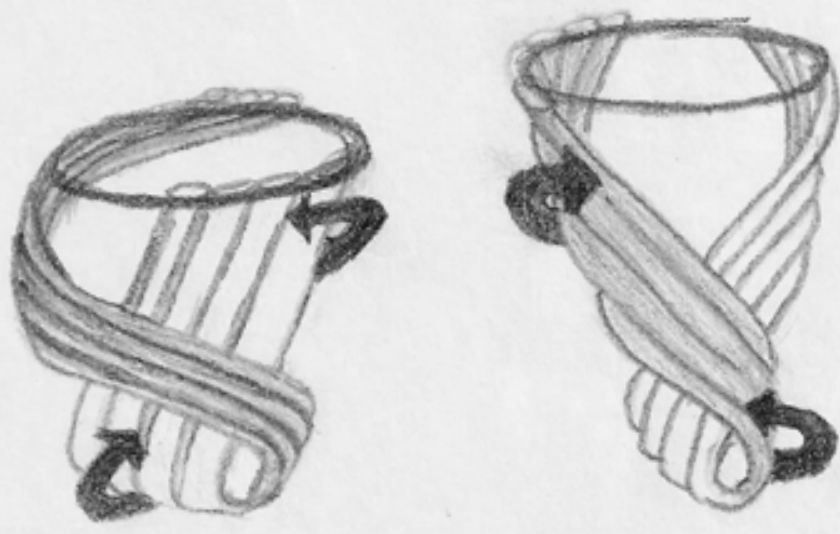

Figure 3. Early diastolic relaxation (left) and early systole (right) in the LV. The longitudinal fibers are oriented in a figure-eight loop, which causes counter-clockwise systolic rotation at the base and clockwise rotation at the apex (left) [5]. Illustration made by Emelie Kihlberg.

The bundles are looped from the base of the heart to the apex and back again and are also divided into descending (light gray in Figure 3) and ascending (dark gray) segments [5]. The subendocardial fibers are oriented in what can be described as a right-handed helix, whereas the subepicardial fibers are oriented in a left-handed helix. During systole, the LV long axis shortens, reducing the volume of the LV cavity, causing blood to be ejected. The movement of the descending segment forces the ascending segment to adopt a curvilinear configuration. Subsequent contraction (thickening of the bundles) uncoils and releases the curvilinear configuration and allows sudden muscular relaxation, resulting in expansion of the ventricular cavity and ventricular filling $[5,6]$. 
The contraction of the muscle-fiber layers generates strain, which is often visualized in a coordinate system in the longitudinal, radial, and circumferential directions [7]. The distribution of the fiber angles and the figureeight loop of the fibers enable the relatively small shortening of the cardiomyocytes to generate a normal left ventricular ejection fraction (LVEF) of $55 \%$ and a large systolic strain in the myocardium [8].

\section{Myocardial infarction and heart failure}

Cardiovascular disease is the leading cause of death in the western world. More than one in three American adults have some kind of cardiovascular condition. Cardiovascular disease causes twice as many deaths as cancer, the second-most-frequent cause of death. The mortality rate due to coronary heart disease is 162 per 100.000 individuals each year in the United States and 119 per 100.000 individuals each year in Sweden (incidence). The mortality rate due to cardiovascular disease may be even higher in other countries; for example, it is reported to be 835 per 100.000 individuals each year in the Russian Federation [9]. Cardiovascular diseases, especially coronary artery disease (CAD), cause many health problems, such as ventricular dysfunction progressing to heart failure. Heart failure is a chronic condition affecting about 200.00o Swedes (prevalence) [10]. The symptoms of heart failure vary widely, from an asymptomatic state to severe and debilitating symptoms of fatigue and shortness of breath even at rest [11].

The coronary arteries supply the myocardium with oxygen and nutrients. The blood flow is regulated to respond to the instantaneous metabolic need. If the blood flow cannot support the metabolic need, ischemia occurs. Insufficient supply of oxygen causes the metabolism to switch to the anaerobic pathway, which results in the accumulation of metabolites such as lactic acid and a drop in the $\mathrm{pH}$ of the tissue. The drop in $\mathrm{pH}$ is a powerful stimulus for vasodilatation. If the supplying vessels cannot dilate because of a stenosis or occlusion, the ischemic cascade (Figure 4) may be initiated [12]. The ischemic cascade involves several steps from a pure metabolic disturbance to chest pain due to cell death, which is a late phenomenon [13]. 


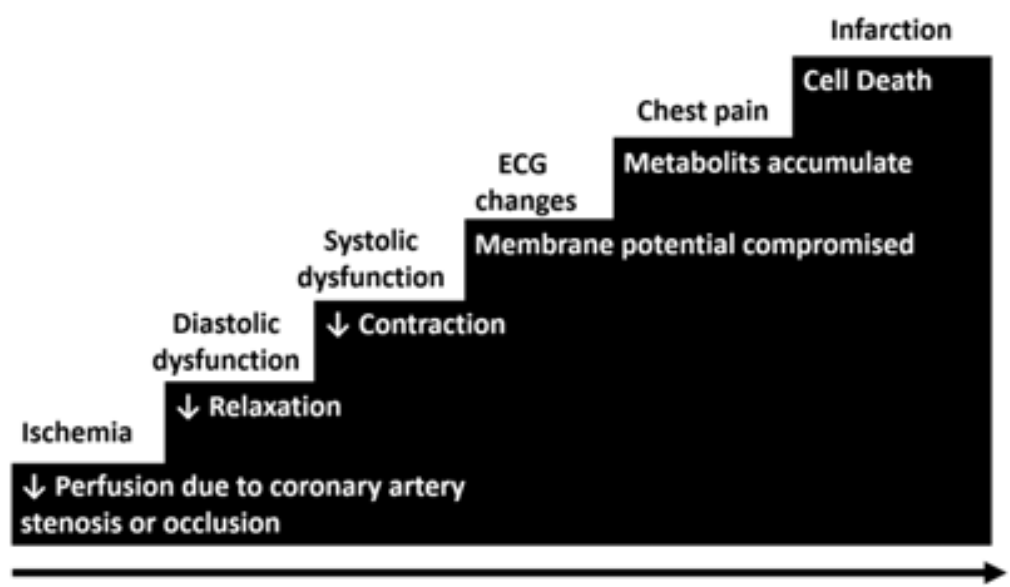

Time

Figure 4. The myocardial ischemic cascade [13].

The ischemic cascade starts when a reduction in perfusion causes a metabolic disturbance [14]. If the perfusion reduction persists, it leads to impaired myocardial relaxation, an early step in diastolic dysfunction [15]. Diastolic dysfunction is an "umbrella" phenomenon, covering the progression from an asymptomatic abnormality in cardiac relaxation to a severe increase in the filling pressure of the $\mathrm{LV}$, which causes the patient to experience breathlessness [16]. The relaxation phase in the cardiac contractile cycle is energy dependent, limited by the supply of energy from adenosine triphosphate (ATP). ATP is needed during relaxation to pump $\mathrm{Ca}^{2+}$ from the cytosol back into the sarcoplasmic reticulum through ATPdependent $\mathrm{Ca}^{2+}$ channels. When ischemia reduces the supply of ATP, relaxation is the first process to be affected [15].

As ischemia persists, creatine phosphate levels and the rate of ATP hydrolysis are reduced. The reduced levels of creatine phosphate and ATP hydrolysis contribute to a continued reduction in the amount of available ATP. The reduced availability of ATP further impacts the ATP-dependent transport of $\mathrm{Ca}^{2+}$, and muscle contraction is impaired further [15]. Diastolic dysfunction refers to abnormal mechanical (diastolic) properties of the ventricle and is present in virtually all patients with heart failure [17]. Failure to maintain oxygen delivery to the mitochondria results in impaired systolic fiber contraction and compromised relaxation.

The shortage of ATP influences the ATP-dependent $\mathrm{Na}+\mathrm{K}+$ pump in the cell membrane. Disturbances in depolarization and repolarization, and ultimately, failure to sustain the membrane potential can now be observed as changes in the electrocardiogram (ECG) [18]. 
Chest pain may be the first symptom that the patient notices, but it is almost the last step in the cascade. The accumulation of metabolites and adenosine eventually cause chest pain [19]. If ischemia persists long enough, it results in irreversible cell rupture and necrosis, starting in the subendocardium and propagating towards the epicardium. In summary, the ischemic cascade describes a sequence of physiological changes that reflect the progression of myocardial ischemia [13].

If ischemia does not progress to myocardial infarction, myocardial contraction may be reduced for prolonged periods by two different mechanisms: stunning and hibernation. Ischemia is due to increased oxygen demand, which can be provoked by heavy work. In a clinical environment, physical stress testing can utilize bicycling or pharmacological provocation (dobutamine infusion) to identify ischemia. Stunning is dysfunction that occurs after an ischemic event in a heart that has normal perfusion when the patient is at rest, without cell death but with impaired systolic contraction [20]. In severe obstructive coronary disease, repeated bouts of ischemia may provoke long periods of stunning. Hibernation is more difficult to demonstrate than stunning. Longstanding ischemia may result in a chronic reduction in resting flow, inducing contraction abnormalities but no cell death. The only way to objectively demonstrate hibernation is by restoring the blood flow and observing a subsequent normalization of LV wall motion.

If the myocardium is already infarcted, the cells are dead and there is no benefit from revascularization; however, if there is a decreased perfusion during stress but the myocardium is viable, as in repetitive stunning and hibernation, revascularization will benefit the patient [18].

The extent and severity of contractile dysfunction after a myocardial infarction are crucial for the long-term prognosis [21]. Contractile dysfunction of the LV is frequently determined with echocardiography and can be expressed as a reduction in LA shortening and in LVEF. The underlying cause of contractile dysfunction is the extent of infarct scarring, which is best determined by magnetic resonance imaging (MRI) [22, 23].

\section{Magnetic resonance imaging}

\section{The MRI experiment}

The smallest element in the periodic table, the hydrogen atom, or proton, has a nuclear spin. The spin can be seen as a rotating charge, which results in a magnetic dipole moment. When an object containing hydrogen is placed in a strong magnetic field, the nuclei will be magnetically affected. The main magnetic field strength in clinical MRI scanners is most often in the range of 1.5-3 Tesla [24]. If an atom has an odd number of pro- 
tons and/or neutrons, a spin can be induced. Because the human body is $75-80 \%$ water, hydrogen is the most common element in the body and is present in all kinds of tissue. Therefore, hydrogen is an excellent nucleus for MRI studies of the body. The water protons form spins that rotate, or precess, at a frequency directly proportional to the main magnetic field strength, the Larmor frequency. Precession occurs in the direction of the main magnetic field, z. Radio frequency (RF) wave at the same frequency as the Larmor frequency, but directed perpendicularly to $\mathrm{z}$, will induce the magnetic dipoles to flip, creating an angle with respect to z. During the application of the RF wave, there is a continuous increase in the flip angle of all spins. Therefore, the desired flip angle can be chosen by setting the amplitude and duration of the RF pulse [25].

The sum of all spins causes the net magnetization. When the RF wave is turned off, the net magnetization slowly returns to its original state. That process of relaxation creates the free induction decay signal. Three important exponential relaxation times can be identified. T1 denotes the time that it takes the longitudinal (along the main magnetic field) magnetization to return to $63 \%$ of the original magnetization. T2 denotes the time that it takes for $37 \%$ of the transverse magnetization (perpendicular to the main field) to be neutralized. $2^{*}$ denotes the time that it takes for the free induction decay to fade away. Generally, in the body, T1 is a few seconds; T2 is in the range of $20-200 \mathrm{~ms}$ for tissues and around $1 \mathrm{~s}$ for water; $\mathrm{T}_{2} *$ is up to a $50 \mathrm{~ms}$ in healthy myocardium but varies among different tissue types and disease states. The component of the magnetization that points in the $\mathrm{x}$ or $\mathrm{y}$ direction, perpendicular to the $\mathrm{z}$ direction, precesses with the Larmor frequency. If all spins precess coherently, all of the microscopic magnetic moments add up to a macroscopic magnetic moment, which induces a signal in antennas (coils) positioned close to the patient. The loss of coherency of all spins is described by T2 relaxation. The return to the original magnetization in the $\mathrm{z}$ direction is described by T1 relaxation [25].

\section{The MRI pulse sequence}

When the magnetic field is varied spatially by a few permille, the exposed object experiences a magnetic field gradient in which each point has its own Larmor frequency along the gradient. That phenomenon is used to select a slice and one of two directions in the image matrix of the selected slice. For the second direction, the signal is encoded by phase changes that occur when a gradient is applied at the start of the sequence and then repeated many times with different increments of the gradient amplitude. The detected signal has different frequencies and phases, which uniquely identify each voxel. Image reconstruction is performed with an initial readout of k-space followed by Fourier-transformation to image space. The signal characteristics from various parts of the object can then be reflected in the image. By transmitting RF waves, changing the gradients, 
and listening for a signal at the right moment, the complete MRI sequence of transmitting and receiving is built up [26].

Various effects can be enhanced or suppressed. Different sequences emphasize different tissue characteristics. For example, in a T1-weighted image, T1 relaxation is highlighted while $\mathrm{T} 2$ properties are suppressed; a strong T1 signal is bright in the image. In most investigated conditions, there are elements of $\mathrm{T} 1$ and $\mathrm{T} 2$ that can change over time because of physiological changes such as perfusion, diffusion, or movement due to respiration or muscle contraction. Such physiological effects are normally suppressed in MRI studies, but they are sometimes the primary characteristics to capture. In a knee examination, for example, the perfusion through the popliteal artery can interfere with the image of the cartilage, but in an examination of the aorta, the blood flow itself may be of primary interest [27].

\section{The spin echo sequence}

The design of an MRI sequence can best be explained using the example of the spin echo sequence, which his shown in Figure 5. Five timelines are drawn along the $x$-axis. The top line in the figure depicts the transmitting RF pulse. Two RF events occur during a cycle: a 90-degree pulse followed by a 180-degree refocusing pulse. The period between a 90-degree pulse and the 90-degree pulse of the following cycle is the repetition time (TR). The TR needs to be sufficiently long to allow the longitudinal magnetization to recover (T1 relaxation). The duration of the TR in a spin echo sequence is typically between $500 \mathrm{~ms}$ and $5000 \mathrm{~ms}$. In the figure, the sliceselect gradient (Gs) is displayed below the RF line. The Gs is turned on simultaneously with the 90-degree pulse and the 180-degree refocusing pulse. The Gs restricts the RF pulse to only excite the slice at the Larmor frequency. The third line in the figure shows the phase-encoding gradient (Gp), which changes for each cycle until enough data is acquired. During the Gp, the frequency-encoding gradient (Gf) is also switched on. The Gf is also activated when a signal (echo) is detected. The time elapsed between the first 90-degree pulse and the echo is the echo time (TE), which has a duration of $10 \mathrm{~ms}$ to $200 \mathrm{~ms}$. The refocusing pulse is always transmitted after half of the TE has elapsed [25]. 


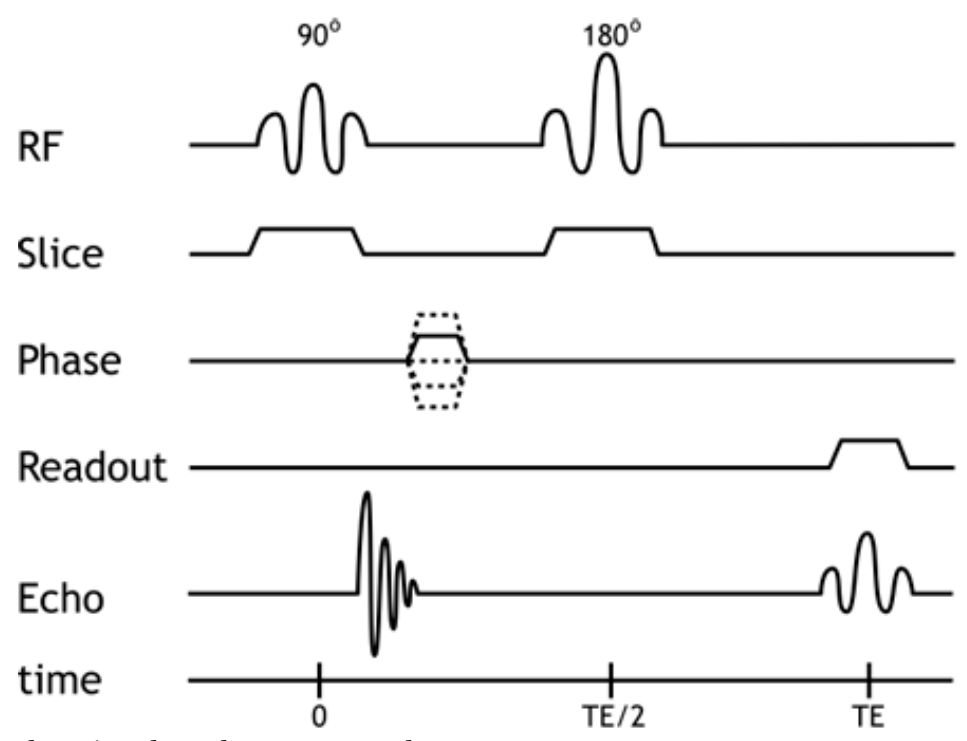

Figure 5. The spin echo pulse sequence scheme

\section{The gradient echo sequence}

In a gradient echo sequence, a gradient in the frequency encoding is switched on immediately after the excitation pulse. Dephasing occurs when spins with different frequencies recover to their initial magnetization. Thereafter, an opposing gradient is applied, which rephases the spins to form a signal. In gradient sequences, the TR is between $15 \mathrm{~ms}$ and $30 \mathrm{~ms}$, and the TE is shorter than in a spin echo sequence. The excitation pulse "flips" the spins at an angle less than 90 degrees, usually in the range of 15 to 45 degrees [28].

\section{Inversion recovery}

Prepulses can be applied before the excitation pulse (e.g. an inversion pulse that inverts the net magnetization by a $180^{\circ}$ pulse). After the prepulse is turned off, the net magnetization returns from a maximum negative value, through the zero level, to a maximum positive value. The relaxation varies for tissues that have different $\mathrm{T} 1$ times. At the inversion time (TI), a particular tissue has zero net magnetization and cannot be excited when the excitation pulse is delivered. The non-excitable tissue then appears black in the image [29].

\section{MRI safety}

Because MRI does not employ ionizing radiation, referring physicians may consider MRI examinations to pose no risk to the patient [30]. There are, however, some important aspects to consider. The RF signal deposits energy in the tissue, which can result in local and general warming. All MRI scanners provide mechanisms for limiting the rate of energy absorp- 
tion in tissue, but the heating effect should be taken into consideration in, for example, patients with fever and those who are critically ill or anesthetized with controlled respiration [31].

When the gradients change polarity, vibrations in the gradient coils produce noise, which becomes louder with increasing slew rate [30] and field strength [32]. Patients must therefore wear ear protectors [33]. Specific considerations should be taken when patients with tinnitus and hearing loss are examined.

The changing gradients can also cause nerve stimulation, which can have discomforting effects such as finger contractions [30]. At high magnetic field strengths, such as 7 Tesla, vestibular effects are common [34].

The magnet of the scanner is cooled by helium, which may inadvertently escape from its container. The helium is in liquid form and cooled to a temperature close to -270 degrees Celsius. Any leakage can therefore cause serious cold damage. When helium boils off, the volume expands 700 times, potentially replacing oxygen in the air surrounding the patient and thus causing suffocation. Several safety devices are used to discharge helium leakage outside the building [35].

Patient implants may be affected by the examination. If the implant is magnetic, the magnetic field induces a force to align the implant with the main magnetic field (torque). The implant may also pick up energy from the RF pulse, and depending on several factors such as orientation, length, and composition, very high temperatures may occur, so-called hot spots, which may even cause burns. Active implants like pacemakers and insulin pumps may also stop functioning [36].

Paramagnetic external equipment can have a devastating effect if it gets close to a magnetic scanner. Depending on the material and mass, strong forces can move such equipment at high speed [25], which may be fatal to the patient in the scanner tunnel [37].

To visualize certain functions and pathologies, gadolinium (Gd) contrast agents are injected. Gd is a rare metal, which in ionized form is enclosed within a chelate. Under certain conditions, Gd ions may transfer into another chelate in the body. In patients with renal failure, Gd has been shown to cause nephrogenic systemic fibrosis (NSF), which is a very unusual but severe condition that can be fatal. NSF has almost completely disappeared since the introduction of precautions such as the avoidance of Gd in patients with reduced kidney function, reduced dosing, and general switching to agents in which Gd is connected to a stable chelate. However, recent findings show that Gd is stored in tissues such as skin, bone, and brain, even in patients with normal renal function [38]. The European Medicines Agency recommend restricted use of linear chelates 
because of the lower stability of those agents as a chelating compound [39].

It may be necessary to investigate pregnant women with MRI. A Canadian study followed the outcomes of 1700 MRI examinations of pregnant women and did not find differences in the frequency of neoplasm, congenital anomalies, or hearing/vision loss compared with the general population; however, exposure to a Gd agent increased the risk of skin conditions and stillbirths [40]. Therefore, based on the principle of risk reduction, MRI examinations are usually avoided in pregnant women [41].

\section{Cardiovascular MRI}

Cardiovascular MRI (CMR) is routinely used in a variety of heart diseases and, in contrast with computed tomography (CT), does not require the use of ionizing radiation [42, 43]. Initially, CMR was used for flow measurements, but it was soon learned that CMR has superb precision in the measurement of cardiac ventricular volumes, left ventricle wall mass (LVM), and ejection fraction, which shows the effects of various cardiac interventions [44]. After the injection of Gd contrast, delayed imaging shows the size of the infarct scar [45], which is of major prognostic importance [23]. Furthermore, CMR has the advantage of a wide coverage such that the entire heart can be depicted, which is difficult to achieve with echocardiography [46].

Magnetic resonance angiography with and without Gd contrast agent can be used to show details of complicated congenital cardiac abnormalities [47]. The phase contrast sequence permits the velocity and volume of the blood flow to be recorded with high accuracy [48]. Usually, flow is measured perpendicularly to a slice, but advanced techniques allow even a four-dimensional volume to be collected, permitting flow velocity [49], turbulence [50], and kinetic energy [51] to be monitored in the large vessels.

Myocardial tissue characteristics can be assessed in a number of ways using CMR. Various substances accumulate in the myocardial interstitium as an effect of metabolic disturbances. Iron deposits can be measured using quantitative relaxometry methods [52]. T2* measurement has revolutionized the surveillance of treatment effects in thalassemia, helping to avoid heart failure [53]. Relaxometry can also be used to measure fibrosis [54] and to quantify extra cellular volume (ECV) [55]. The measurement of ECV is not yet included in the guidelines for CMR, but its potential to aid in tissue characterization is high. The calculation of ECV requires the injection of Gd. If Gd is injected, first-pass perfusion can be visualized and quantified [56]. Perfusion delays can be detected at rest or under pharma- 
cological stress (adenosine) and help in the evaluation of chest pain. Dobutamine stress testing with assessment of wall motion is another technique to detect ischemia, and a low-dose dobutamine test may be used to assess viability [43].

Spectroscopy of the heart detects the spin of molecules involved in metabolism. The result of spectroscopy is generally expressed graphically, but spectroscopic imaging is also possible. Spectroscopy of phosphorus, instead of proton, allows the calculation of ATP consumption [57], although the technique is difficult and has not yet been adopted into clinical imaging.

Hypothetically, it is possible to measure almost all of the steps in the ischemic cascade (Figure 4), but only a few methods are sufficiently robust and used commonly enough for their accuracy to be considered evidence based. In CAD, the two most important parts of a CMR study are cine imaging for LV size and function and a late Gd sequence to detect scarring.

\section{Late Gd enhancement}

If an ischemic insult to the myocardium results in cell death/infarction, the cell membrane disintegrates. When an intravenous Gd agent is administered, contrast washout is delayed in the diseased tissue but normal in healthy tissue. Gd shortens T1 relaxation, resulting in a bright signal on T1-weighted images. Washout is also delayed in inflamed tissue and in fibrotic tissue. For maximum contrast difference between healthy and diseased tissue, the signal from healthy myocardium should be "nulled" by adjustment of the TI so that inflamed or fibrotic tissue that retains Gd appears as bright areas in the image. The TI is individual because of various circulatory conditions, the volume status of the patient, body weight, and other factors [58]. It is sometimes difficult to determine the correct TI manually, so supportive methods need to be developed to support that process.

\section{Strain and torsion}

The clinical assessment of wall motion is based on visual assessment by an experienced observer [47]. The assessment of regional wall motion is essential to every echocardiographic and CMR exam. Despite its frequent use, such assessment is observer dependent. Methods have been proposed to objectively measure hypokinetic wall motion e.g. the echocardiographic speckle-tracking method [59], but visual assessment is still the recommended method [6o]. Therefore, there is a need for objective and quantitative measurements that may increase diagnostic accuracy [61].

The concept of strain is derived from mechanical engineering and is used to describe the three-dimensional (3D) deformation of a very small cube in a very short time. The strain tensor has six components, three along the 
orthogonal axes (x, y, and $\mathrm{z}$ ) and three shear tensors along $\mathrm{x}-\mathrm{y}, \mathrm{x}-\mathrm{z}$, and $\mathrm{y}-$ z. By dividing the myocardium into a large number of small cubes, detailed information can be obtained for each strain tensor at any moment. That process becomes unmanageable for large amounts of information, however, so it is more convenient to use an internal coordinate system based on the heart's natural axes (longitudinal, radial, and circumferential; see Figure 6) and relate the temporal variation to the electrocardiogram cycle [62].

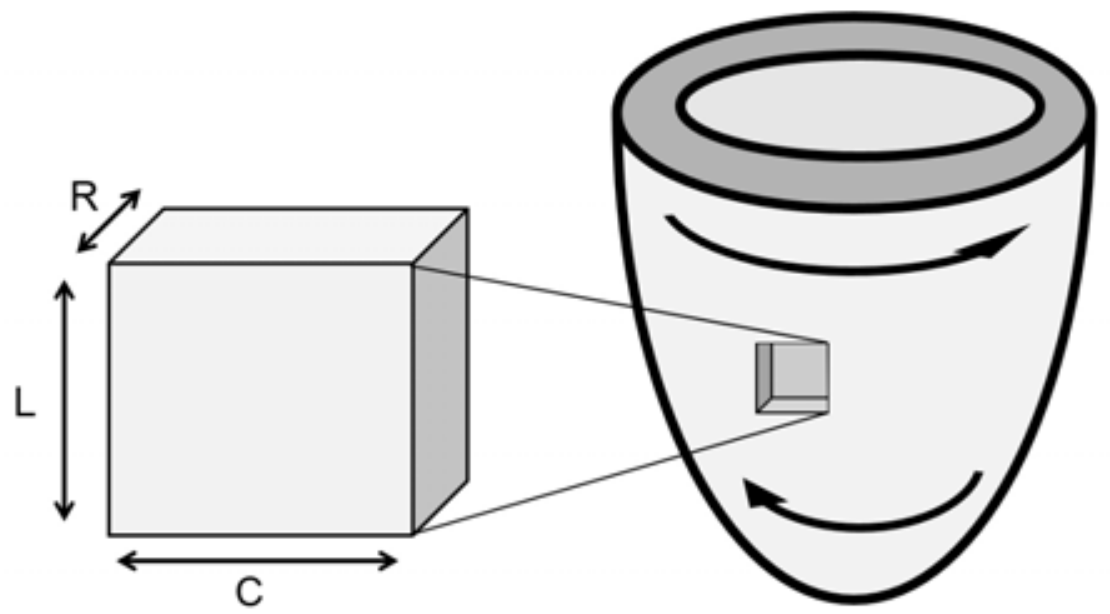

Figure 6. The coordinate system for measuring myocardial strain in the $R=$ radial, $L=$ longitudinal, and $C=$ circumferential directions. The arrows in the schematic ventricle on the right indicate the direction of rotation in end systole.

Strain expresses the percent change in length of a muscle segment and depends on the forces developed in the fiber and the mechanical properties of the surrounding tissue. A positive value for circumferential and longitudinal strain denotes lengthening, whereas a negative value denotes shortening. For radial strain, a positive value denotes thickening, whereas a negative value denotes thinning [63]. In tissue, strain can be related to different coordinate systems; the Euler system uses a coordinate system that is fixed in $3 \mathrm{D}$ space, while the Lagrange system follows a reference image of the object [64]. A third method is engineering strain (see Figure 7). In practice, it may not matter which method is used, but the reference system should be noted to allow a correct assessment of the resulting values. To further complicate assessment, shear strains between different fiber sheets add another set of measurements that are sometimes important. 


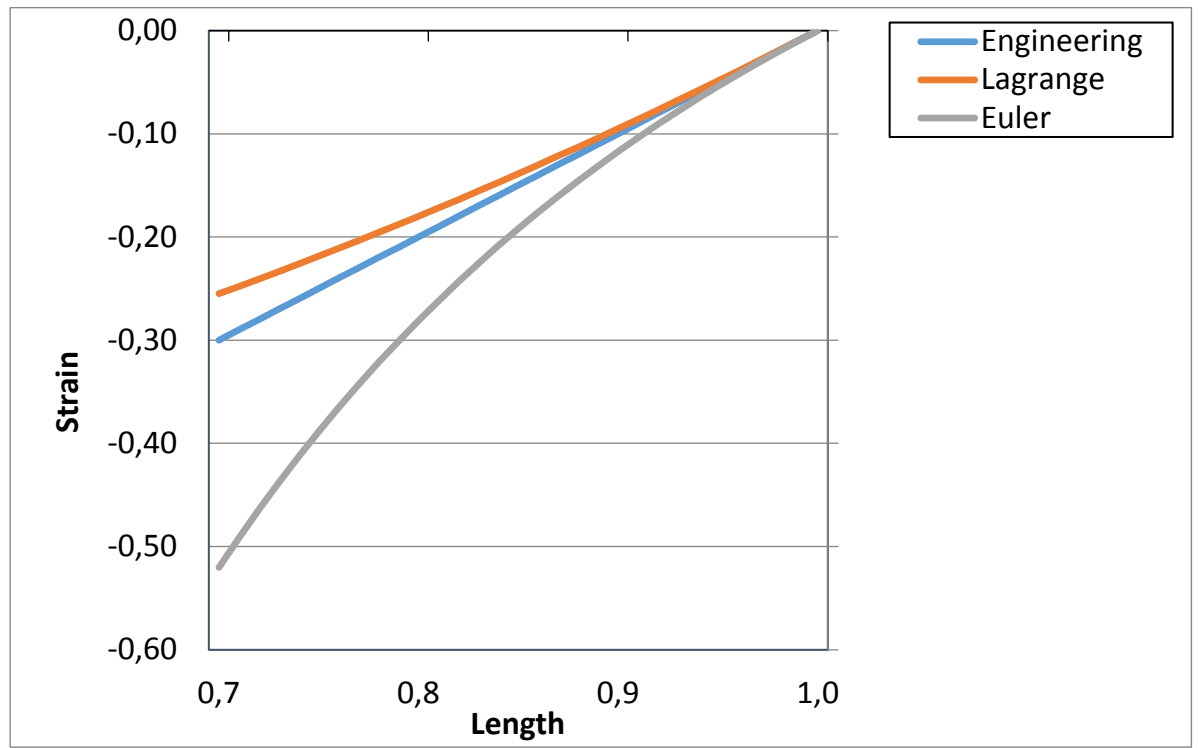

Figure 7. The relationship between strain expressed in the Lagrange, Euler and Engineering systems. Courtesy of Henrik Haraldsson.

Unfortunately, the reference system is not always stated in publications, complicating the comparison of values among different studies.

Myocardial strain can be used to express regional [65] and as well as global [66] myocardial function.

There are five common methods to measure strain by CMR: tagging, (phase) velocity contrast, sensitivity encoding (SENC), displacement encoding with stimulated echoes (DENSE) and "feature tracking" (FT), an image-based method using ordinary cine images.

The tagging sequence labels bands of tissue using a saturation sequence that extinguishes the magnetization in the tissue at one moment in the cardiac cycle. The tags are subsequently deformed along with the deformation of the myocardial tissue [67]. The images can be assessed visually, but image post processing with harmonic phase (HARP) software [68] is often seen as the gold-standard method $[69,70]$.

Velocity contrast measures the velocity of the displacement of cardiac muscle, which can be recalculated into strain. The technique is very similar to flow measurement, but with a much lower velocity encoding because wall velocities are about one tenth that of blood [71-74].

Strain encoding (SENC) [75] is the least disseminated method and uses tagging in the z-direction. SENC measures stretching or compression of the image slice. There are now SENC methods that are part of the cine 
sequence [76] or the late Gd enhancement (LGE) sequence [77] which facilitates clinical availability and quantification.

The DENSE method gives the ability to measure myocardial deformation at a relatively high spatial resolution over the cardiac cycle. The phase of the stimulated echo is directly proportional to the displacement of the tissue. The stimulated echoes encode the displacement over time to store the magnetization vector along the direction of the static magnetic field in order to avoid T2* effects and maintain T1 weighting. DENSE is a phase contrast method with low velocity that demands large gradient moments, which lead to prolonged echo time and phase distortion [78].

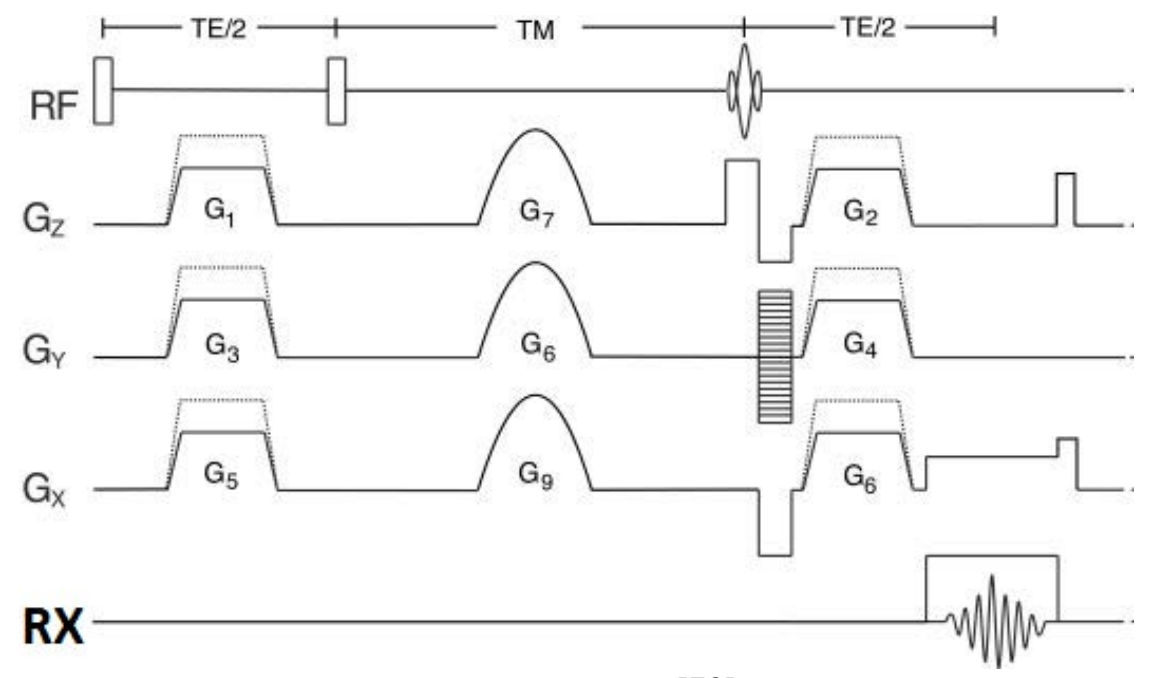

Figure 8. The DENSE pulse sequence from Aletras et al [78].

In Figure 8, the DENSE pulse sequence is plotted. During the gradients G1, G2, and G5, the phase spin is wrapped. The matching gradient pulses G2, G4, and G6 unwrap the phase of the static tissue. The spins that have moved during the time TM keep their phase. When the duration and amplitude of the displacement-encoding gradient pulse are known, the phase differences can be converted to displacement vectors [78].

A DENSE map can be presented based on several aspects such as phase motion, the radial gradient of displacement, and eigenvector direction (strain direction) and eigenvector value (local strain). The direction can be longitudinal, circumferential, or radial. An early study showed good correlation between circumferential shortening obtained with DENSE in healthy individuals and that obtained with tagging in the same individuals [79]. There is so far no available commercial software for the post processing of DENSE measurements [80], however, and the mathematic analysis is rather complicated [79]. Figure 9 shows some images resulting from DENSE post processing. 


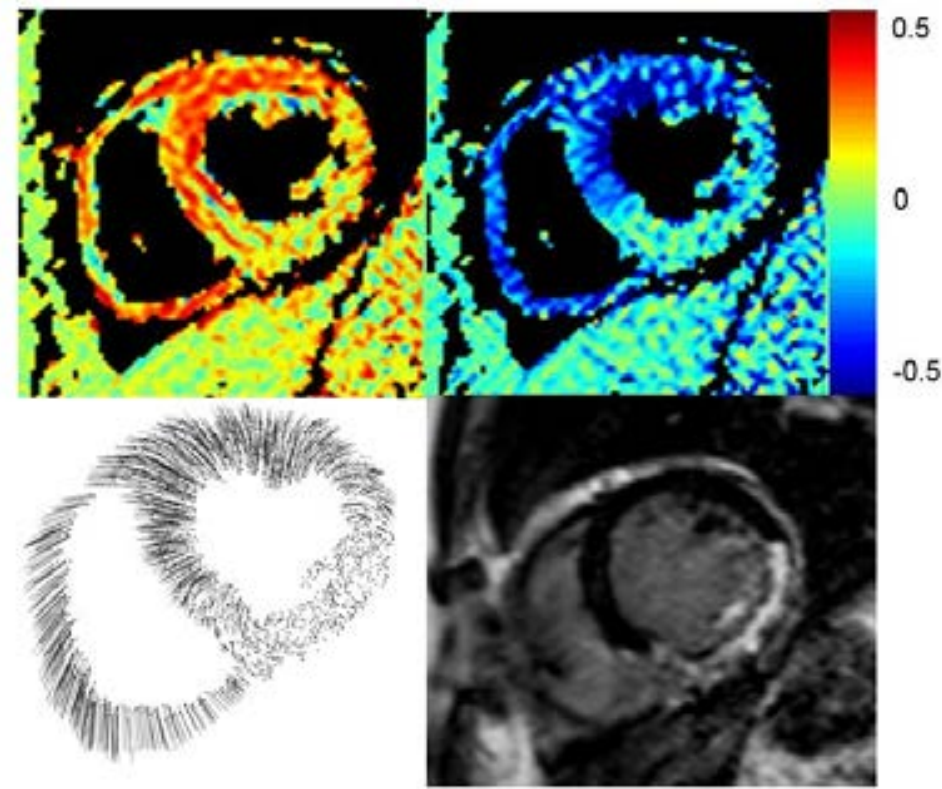

Figure 9. DENSE images with radial strain (top left), circumferential strain (top right), displacement plot (bottom left) and corresponding LGE (bottom right). Courtesy of Andreas Sigfridsson.

The latest technology for measuring strain by CMR is FT, which is based on the image series that is obtained to calculate cardiac chamber volumes and to visually assess myocardial wall motion. The technique identifies image features, such as variation in the tissue signal in relation to 48 points along the myocardial boundaries, which are followed throughout the cardiac cycle [81]. No additional imaging is required, but the disadvantage is that through-plane displacement of the tissue could confuse the algorithm [46].

Torsion has proven to be very useful for assessing the global function of the heart [82, 83]. Several studies have shown its usefulness to display changes with age [84-87], hypertension [88], cardiomyopathy [89], obesity [90], and coronary heart disease [91-93]. Torsion measures cardiac contraction in any mammalian heart [94]. Unfortunately, various researchers define torsion differently [95]. The radius of the cavity has to be included in the equation to allow proper comparison between hearts of different sizes [95].

Torsion can be calculated from measurements produced by tagging, velocity contrast, DENSE, or FT. Parity comparisons have been made between the different methods to calculate strain and torsion, but no study has compared the accuracy of the different methods in the identification of disease. 


\section{MRI from the patient perspective}

The first scientific reports that patients experienced anxiety and panic related to MRI investigations were published in the late 1980s [96]. More comprehensive studies investigating the patient experience of MRI examinations came a decade later. They found that $37 \%$ of patients had moderate to severe anxiety during an MRI examination. The anxiety was associated with claustrophobia, pain, lack of familiarity with the entire situation, and worries regarding the potential result of the investigation [97]. In another early study of 80 first-time patients examined by MRI, $25 \%$ of the patients expressed moderate to severe worry [98]. More than $70 \%$ of radiographers claimed that worry and anxiety is common among patients who undergo MRI [99].

Anxiety seems to be a problem not only for patients who undergo MRI but also for those who undergo CT. The source of anxiety may be related to the health of the patient or to rumors and myths about the investigation. The psychological experience in an MRI scanner is often strong, in part because the examination time for MRI is at least three times longer than that for CT [100]. Patients' previous experience also affects the intensity of the anxiety [101].

There are a few studies of patient experiences in the radiology context [102]. In a quantitative study from 2003, 253 consecutive elective patients reported a $28 \%$ incidence of anxiety regardless of which of the six examination modalities they experienced. There was a significant correlation between the patients' state of health and the patients' anxiety: the worse a patient's estimate of his or her own health, the higher the anxiety. There was no correlation between previous information and anxiety, but reassurance by staff could alleviate anxiety [103]. Anxiety related to the result of the examination was given as the cause of anxiety by most patients in a French cancer-imaging department [104].

Image quality is high on the list of radiographer responsibilities, and patient anxiety is a significant factor affecting image quality [105]. When extra information was provided to patients undergoing MRI, anxiety did not always decrease, but image quality improved [106]. In another attempt to alleviate anxiety, extra video information was given to patients preparing for MRI. No relief of anxiety could be demonstrated, but the patients felt more relaxed [107]. Extended information about the MRI procedure together with instructions for relaxing has been shown to decrease anxiety [108-110]. Information is intended to calm patients, but it is not always successful and should be given individually and when needed [111]. Information given orally seems to work better than printed material [112]. When giving information, it is important to achieve a status of "information saturation," meaning that all questions have been answered [113]. 
Törnqvist [106] proposed that the loud noise during MRI examinations causes increased anxiety. A small discomfort can be amplified into a difficult experience, most likely because of the confined environment in the scanner tunnel, where up to $30 \%$ of MRI patients experience claustrophobia [100]. That figure is far higher than the $4 \%$ of the general population that is reported to experience claustrophobia [114]. Newer MRI scanners cause fewer problems [106], thanks to shorter and wider tunnels and less noisy gradient coils [111]. The design of the scanner has been investigated in several studies. One randomized study with patients who experience narrow spaces negatively showed that an open scanner design resulted in a tendency towards less claustrophobic feelings [115]. Another study showed that a newer and shorter scanner resulted in fewer prematurely interrupted examinations and less need for sedation [116]. An open scanner design - without a tunnel - used for patients with claustrophobic feelings reduced the anxiety level significantly and decreased the number of aborted examinations by $86 \%$ [117].

Several anxiety-provoking mechanisms are at play in patients who undergo MRI. One important mechanism is the experience of losing control $[118,119]$. Patients can gain a feeling of control when they are allowed to decide when to hold their breath. In one study, almost half of the patients preferred self-determination in breath holding [119]. In held-breath acquisitions, the effectiveness increases when patients, both children and adults, receive visual feedback on their breathing pattern [120]. Additional ways to achieve patient control are to let the patients decide their position on the examination tabletop and how to enter the tunnel. For patients who are anxious, being supine [111] and entering the tunnel feet first [98] seem to be comforting.

In summary, between one-fourth and one-third of all patients entering a radiology department are anxious [103]. The anxiety is enhanced by long, complex investigations such as MRI [121]. Anxiety can be relieved, especially if the MRI personnel create a trusting atmosphere and dialogue $[112,122]$.

\section{Ethical considerations}

Two large patient cohorts, "Mr-STEMI" and "Doppler-CIP," constitute the basis for this thesis. Both cohorts were approved by the regional ethical review board in Linköping, which is a free-standing public body charged with vetting research on humans according to Swedish law [123]. All patients were informed both orally and in writing before signing the consent form. In addition, a separate approval was obtained to study wall motion with CMR in healthy volunteers and patients. The result of the MRI examinations in the Mr-STEMI and Doppler-CIP cohorts were reported to the 
treating physicians and had strong clinical value for patient care. The participants had the opportunity to decline participation without giving any reason. The potential risks related to MRI were harmful effects of strong magnetic fields, biological effects of injected Gd contrast, and the consequences of follow-up of mostly benign incidental findings. The advantage of participation was the potential for early detection of significant cardiovascular or oncologic disease and early treatment. The potential risk to the participants was deemed low, because all MRI investigations are performed with due consideration of MRI safety by well-trained MRI staff. Before the injection of Gd, glomerular filtration rate (GFR) was calculated, and inclusion was not considered when the GFR was less than 30 $\mathrm{ml} / \mathrm{kg} / \mathrm{min} / 1.73 \mathrm{~m}^{2}$. The participants were not considered to be exposed to excessive risk and could request termination of participation at any time, fulfilling the intentions of the declaration of Helsinki [124]. 
Magnetic Resonance Imaging of Myocardial Deformation and Scarring in Coronary Artery Disease. 


\section{AIMS}

The overall aim of this thesis was to validate MRI sequences and post processing for the study of cardiac function, deformation and scarring.

The specific aim for each study was to:

Paper 1

Measure and display the absolute T1 relaxation in the whole heart within a single breath hold based on a $3 \mathrm{D}$ phase-sensitive inversion-recovery (PSIR) acquisition of LGE.

\section{Paper 2}

Determine the sensitivity and specificity of strain derived from DENSE for the detection of myocardial scarring in patients with a high likelihood of CAD.

\section{Paper 3}

Compare measurements of circumferential strain derived from DENSE, tagging, and FT with clinical parameters such as LV volumes, LVEF, and the presence and extent of myocardial scarring.

\section{Paper 4}

Compare torsion derived from DENSE, tagging, and FT with global measurements of cardiac function in a population with a high likelihood of CAD. 
Magnetic Resonance Imaging of Myocardial Deformation and Scarring in Coronary Artery Disease. 


\section{METHODS}

\section{Data collection}

The data collection for Paper 1 was based on a combination of computer simulation, phantom scans, and clinical scans in a subgroup of 18 patients from the Mr-STEMI cohort, which included patients with ST-elevation myocardial infarction who were treated with primary percutaneous coronary intervention and scanned with CMR within 4-8 weeks [125].

The data collected in Papers 2-4 was based on patients in the DopplerCIP cohort [126], which was part of a multicenter study under the EU FP 7 program. Patients were recruited from February 2010 to March 2012 in Linköping, Sweden, one of the sites participating in the Doppler-CIP study. In total, 197 patients were recruited, 186 of whom underwent MRI. Patients were asked to participate if any of these conditions applied: 1 . If they had a high likelihood (>15\%) to suffer from CAD according to the $\mathrm{Eu}-$ ropean SCORE criteria and were on the waiting list for myocardial scintigraphy, if 2. they had a positive exercise test and a high likelihood of CAD, or 3. had had a myocardial infarction, or 4. had coronary heart disease demonstrated on an angiogram. Exclusion criteria were the use of a pacemaker, atrial fibrillation, unwillingness to participate, claustrophobia, or an estimated GFR less than $60 \mathrm{ml} / \mathrm{kg} / 1.73 \mathrm{~m}^{2}$.

During the period from November 2010 to March 2012, 125 patients were examined with a complete MRI protocol for Paper 2. Thirty-five tagging datasets from those patients were not analyzed in the core lab for logistical reasons, which left 90 patients for complete strain analysis in Paper 3. Of those 90 patients, 42 had poor tagging quality in either the basal slice or the apical slice, preventing the analysis of torsion. Twenty patients had DENSE images of inferior quality. The remaining 48 patients with complete torsion data were included in Paper 4.

The mean age of the 125 patients in Paper 2 was 67 years (range 49-85 years); 98 were male (78\%); 57 had more than $1 \%$ positive LGE in at least one segment; and 34 (27\%) had at least one segment with a large LGE uptake exceeding 50\% of the segment wall area, also know as "transmurality". Twenty-three patients showed no evidence of CAD based on wall motion, blood pressure, LVEF, LVM, and absence of LGE. That subgroup was considered free from $\mathrm{CAD}$ and was selected as the control group

In Paper 3, 65 (72\%) of the 90 patients were male. The average age was 76 years (range 53-85 years). Twenty-four patients had positive LGE > 50\% 
of the segment wall area, which affected 69 segments. Thirty-five patients had an LVEF below $55 \%$.

Of the 48 patients in Paper 4, 33 were male (69\%) and 9 (19\%) had positive LGE > 50\% of the segment wall area. Eleven patients (23\%) had an LVEF below 55\%, and 11 (23\%) patients had normal blood pressure, LVM, $\mathrm{EF}$, wall mobility, and no signs of positive LGE.

\section{MRI}

A single 1.5 Tesla MRI scanner (Philips Achieva Nova Dual, Best, the Netherlands) with a five-element coil was used for all data collections. In Paper 1, phantom studies preceded the patient examinations. Gd was diluted in water and $2.5 \%$ agarose solution and filled into a test tube (phantom). Standard inversion-recovery measurements of the phantoms produced T1 relaxation times in the range of 228-754 ms. The patients were investigated with 3D PSIR [127] implemented using a 3D turbo field-echo planar imaging (TFEPI) sequence with an echo-planar imaging (EPI) factor of 3 and a TFE factor of 23. TR/TE was 9.4/4.2 ms, and the shot duration was $215 \mathrm{~ms}$ per heartbeat. The pixel size was $1.6 \mathrm{~mm} \times 1.6 \mathrm{~mm}$ reconstructed into $1.1 \mathrm{~mm} \times 1.1 \mathrm{~mm}$. The slice thickness was $10 /-5 \mathrm{~mm}$, and the sense factor was 2 , which produced 12 slices from a breath hold of $24 \mathrm{~s}$ at a heart rate of 60. The same sequence was used for the phantoms, with a heart-rate simulator, and the patients. The reference sequence was a standard 3D TFEPI sequence with nine different inversion times from 50 $\mathrm{ms}$ to $2900 \mathrm{~ms}$. TR/TE was $3000 / 29 \mathrm{~ms}$; the EPI factor was 13; and the flip angle was 90 degrees. All of the patients were scanned using the same $3 \mathrm{D}$ TFEPI sequence, but the number of slices varied for 12 to 16 , depending on the heart rate and size.

In all four papers, LGE images were acquired with a $3 \mathrm{D}$ inversionrecovery turbo field-echo (IR-TFE) sequence with a TR/TE of 4.4/1.3 ms, a TFE factor of 43, a scan-shot duration of $184 \mathrm{~ms}$ per heartbeat, a sense factor of 2, a pixel size of $1.4 \mathrm{~mm} \times 2.0 \mathrm{~mm}$ reconstructed into $1.1 \mathrm{~mm} \times$ $1.1 \mathrm{~mm}$ in 17 slices with a thickness/gap of $10 /-5 \mathrm{~mm}$ during 17 heartbeats.

In Papers 2-4, the patients underwent cine imaging, tagging, DENSE, and LGE. The cine images were acquired with a balanced steady-state free precession (SSFP) sequence covering the whole heart in the short-axis (SA) plane but also applied as three long axis views (2-, 4-, and 3-chamber view). Typical parameters were: TR/TE 3.6/1.81, flip angle 60 degrees, pixel size $1.5 \mathrm{~mm} \times 1.6 \mathrm{~mm}$ reconstructed into $1.2 \mathrm{~mm} \times 1.2 \mathrm{~mm}$, slice thickness $6 \mathrm{~mm}$, slice distance $2 \mathrm{~mm}$, and mean temporal resolution 43 ms. 
Tagging images were obtained with the complementary spatial modulation of magnetization (CSPAMM) sequence applied in three SA slices equally spaced from the apex to the base. Typical scanning parameters were: TR/TE 4.6/2.1, flip angle 15 degrees, pixel size $2.0 \mathrm{~mm} \times 2.0 \mathrm{~mm}$ reconstructed into $1.3 \mathrm{~mm} \times 1.3 \mathrm{~mm}$, slice thickness $6 \mathrm{~mm}$, and intertag distance $8 \mathrm{~mm}$. The mean temporal reconstruction was $43 \mathrm{~ms}$. Tagging was used in Papers 3 and 4.

The DENSE sequence was planned with the same orientation as the tagged images, with three SA slices between the base and the apex. The sequence was based on three balanced multipoint encodings [128] and threefold spatial modulus of magnetization (3-SPAMM) in each direction [129] with fat suppression using a water-selective RF pulse as the first RF pulse in the block. The readout was spiral using six arms with an interleave of $8 \mathrm{~ms}$ [130]. The flip angle was set to optimize signal-to-noise ratio (SNR) for all excitations [131]. TR/TE was set to 11.2/1.27 ms. Throughplane dephasing was $0.25 \mathrm{~Hz}$, and the in-plane displacement strength was $0.30 \mathrm{~Hz} /$ pixel. The pixel size was $2.7 \mathrm{~mm} \times 2.7 \mathrm{~mm}$ reconstructed to 1.4 $\mathrm{mm} \times 1.4 \mathrm{~mm}$ with slice thickness $6 \mathrm{~mm}$. The duration of the acquisition was 18 heartbeats. The sequence used a cine approach with only three time points to gain SNR [132]. The first time point was $45 \mathrm{~ms}$ before closure of the aortic valve; the second time point was exactly at valve closure; and the last time point was $45 \mathrm{~ms}$ after the closure of the valve.

\section{MRI Analysis}

In Paper 1, SyMRI Cardiac Studio (SyntheticMR AB, Sweden) was used as a plug-in in IDS5 PACS (Sectra Imtec, Sweden). The image analysis assumed that a region of interest (ROI) was positioned in the remote healthy part of the myocardium. The settings were adjusted to obtain a signal from the ROI in healthy myocardium close to zero, which determined the TI and the settings for the original LGE acquisition. The image created with SyMRI Cardiac Studio was called a synthetic image. The same software was used for the relaxometry of the test tubes and the myocardium. The fitting algorithm was based on the least mean square method. In addition, Monte Carlo simulations were performed to determine the influence of arrhythmia on the relaxometry measurements. The effect of slight arrhythmia on post-Gd in vivo images could be assessed by varying the heart rate randomly by $\pm 5 \%$.

The DENSE analysis for Papers 2-4 was built on a MATLAB (R2010b, Mathworks, Natick, MA, U.S.A.) script [133]. Magnitude and complex images were imported into the script in DICOM format. The analysis was divided into four user-interaction steps. First, the orientation of the six different views (basal, mid and apical SA views as well as 2-,3-, and 4chamber views) was confirmed. Then, the myocardium was manually de- 
lineated in the endocardial and epicardial contours repeatedly in all six views and in three temporal phases. Two phase maps appeared in the user interface, one for each phase direction in the plane. In the third step, the user specified anatomical landmarks such as the apex and the base in the long axis views as well as the cavity center and the anteroseptal attachment of the right ventricle on the septum in the SA views. Then, Lagrangian strain was presented in three directions (radial, circumferential, and longitudinal) in 16 segments [134]. From the SA images, twist could also be calculated as the differences in rotation between the basal and apical slices. The torsion was obtained by dividing the twist by the distance between the slices. The delineation of the endocardium and the epicardium for the strain analysis was made based on the consensus of two investigators. To determine the variability, the analysis of the dataset was repeated 10 times, and nine patients were scanned twice.

Tagged images were analyzed using the HARP software (Diagnosoft Inc., Palo Alto, CA, U.S.A.). The first step was an automatic k-space filtering to increase the contrast in the image. For each slice, the endomyocardium and epimyocardium were manually delineated. A 24-point mid-wall contour was automatically defined and then propagated and automatically adjusted over the other time phases. If necessary, the propagated delineated contour was manually corrected. Strain was calculated for $16 \mathrm{LV}$ segments [134]. For Paper 4, the rotation was obtained from the mid-wall line and its 24 points over time, and the rotation difference between the apical and basal slices gave the twist. Torsion was obtained by dividing the twist by the distance between the apical and basal slices.

For Papers 3 and 4, strain and torsion were obtained from the SSFP cine images by tracking features in the image using the 2D-CPA MR v1.2 TomTec software (TomTec Imaging System, Munich, Germany). Endocardium and epicardium were delineated in diastole, and the software followed the displacement of 48 points at the endomyocardial contour. Lagrangian strain was calculated for both boundaries, and, in order to obtain transmural strain, a mean value was averaged from the endocardial and epicardial strain. Rotation was also given for the endocardium and epicardium separately. Transmural rotation was calculated by averaging the rotation of the endocardium and epicardium [135]. The difference in rotation between the basal and apical slices gave the twist, which when divided by the distance between the slices produced the torsion. The choice of which slice to use per level was determined by the position and image quality.

The ventricular volumes used for Papers 2-4 (i.e. the end-systolic and end-diastolic volumes and the LVEF) were determined from the SA cine images [136] using the Extended Work Station software (Philips 
Healthcare, Best, the Netherlands). Wall motion was determined visually based on qualitative assessment where $1=$ normal, 2 hypokinetic, $3=$ akinetic, and 4 = dyskinetic [137].

The extent of positive LGE in Papers 2-4 was determined using the Segment v1.9 R2966 software (Medviso AB, Lund, Sweden) [138]. An increase in signal intensity was automatically detected and manually corrected if needed [139]. Four subgroups were defined based on the area of LGE uptake, measured as a percentage of the wall-segment area: 1-25\%, $26-50 \%, 51-75 \%$, and $>75 \%$. A further subgroup was defined for the segments that had LGE $>50 \%$.

\section{Statistics}

Analysis of variance with Bonferroni correction was used in Paper 2 for multiple comparisons when the data were normally distributed. For interobserver and scan-rescan variability, the intra-class correlation coefficient (ICC) was employed. Receiver-operator characteristics were calculated for LGE transmurality, with $>50 \%$ as the end point. Regression curves were plotted to visualize the relationship between LVEF and global strain. Differential strain was introduced in Paper 2 as the difference between a given segment and the mean value of the corresponding segment in the control group. In Paper 3, the data was not normally distributed, according to analyses of skewness and kurtosis, which necessitated the use of non-parametric methods such as the Spearman rho correlation, the Wilcoxon signed rank test, and simple linear regression. The data in $\mathrm{Pa}-$ per 4 was normally distributed, allowing Pearson correlation, t-test, and simple linear regression to be used. The statistical analyses were performed using SPSS 20-24 (IBM Corp, Armonk, NY, U.S.A.). The significance level was set to 0.05 , unless otherwise indicated. 


\section{RESULTS}

\section{Paper 1}

In Paper 1, test tubes filled with Gd-doped water were used as phantoms. The phantoms produced T1 relaxation times in the range of 228-754 ms. The phantoms were scanned to optimize the scanning parameters. A flip angle between 15 and 20 degrees resulted in good SNR and stable relaxometry. A flip angle exceeding 20 degrees underestimated the T1 relaxation time, whereas a flip angle below 10 degrees overestimated the T1 relaxation time.

The effect of TI on the T1 measurement was also tested using the phantoms. A TI below $300 \mathrm{~ms}$ overestimated $\mathrm{T} 1$ when $\mathrm{T} 1$ was over $500 \mathrm{~ms}$. The measured $\mathrm{T} 1$ was stable and close to the expected value when the TI was between $300 \mathrm{~ms}$ and $600 \mathrm{~ms}$.

The Monte Carlo simulations with different heart rates yielded a variance of $\pm 4 \%$ for a T1 of $300 \mathrm{~ms}, \pm 7 \%$ for a T1 500 of $\mathrm{ms}$, and $\pm 10 \%$ for a $\mathrm{T} 1$ of $700 \mathrm{~ms}$. In general, T1 was underestimated at higher heart rates (90 beats per min).

By following the Gd washout for 30 min after injection, differences between healthy and damaged myocardium could be seen after only a few minutes. T1 decreased exponentially for $10 \mathrm{~min}$, after which it remained stable until $25 \mathrm{~min}$ after the injection.

The synthetic images and the standard LGE images showed great similarities among the 18 patients (see examples in Figure 10). There was no significant difference in the contrast-to-noise ratio, and visual assessment of the pathology showed similar results. The standard LGE images had significantly higher spatial resolution, however, and an almost complete coverage of the LV. The 3D PSIR sequence could produce 12 slices within a reasonable breath hold, covering $60 \mathrm{~mm}$. 

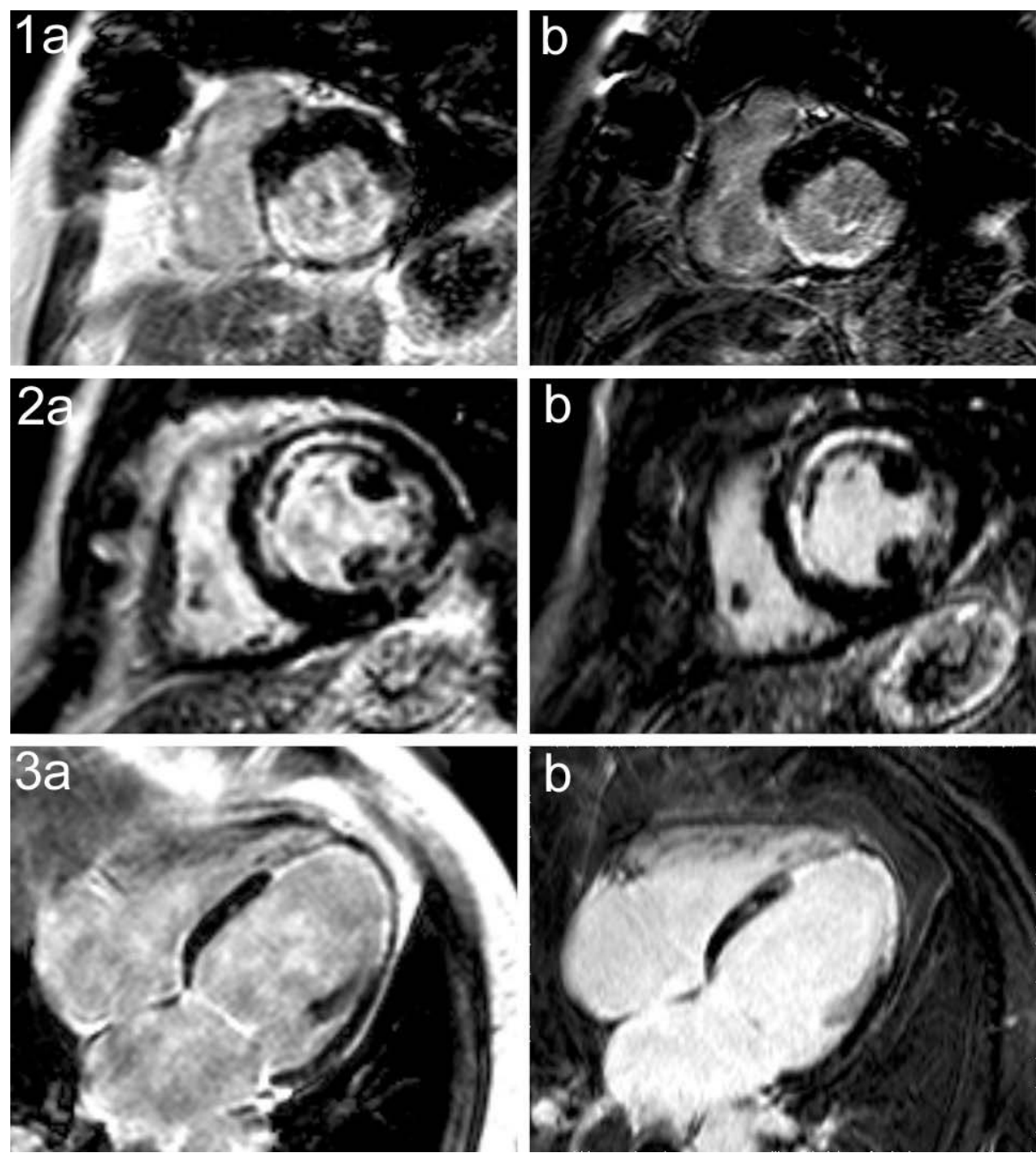

Figure 10. Three examples of synthetic LGE images (a) and the corresponding original LGE images (b). The pathological enhancement showed great similarities.

\section{Paper 2}

In Paper 2, circumferential strain was measured based on three SA slices and assessed both globally and regionally in a population with a substantial risk of CAD. The sensitivity and specificity for detecting LGE $>50 \%$ of the wall area per segment was studied using the area under the curve (AUC) from the receiver-operator characteristic (ROC) curve shown in Figure 11. 


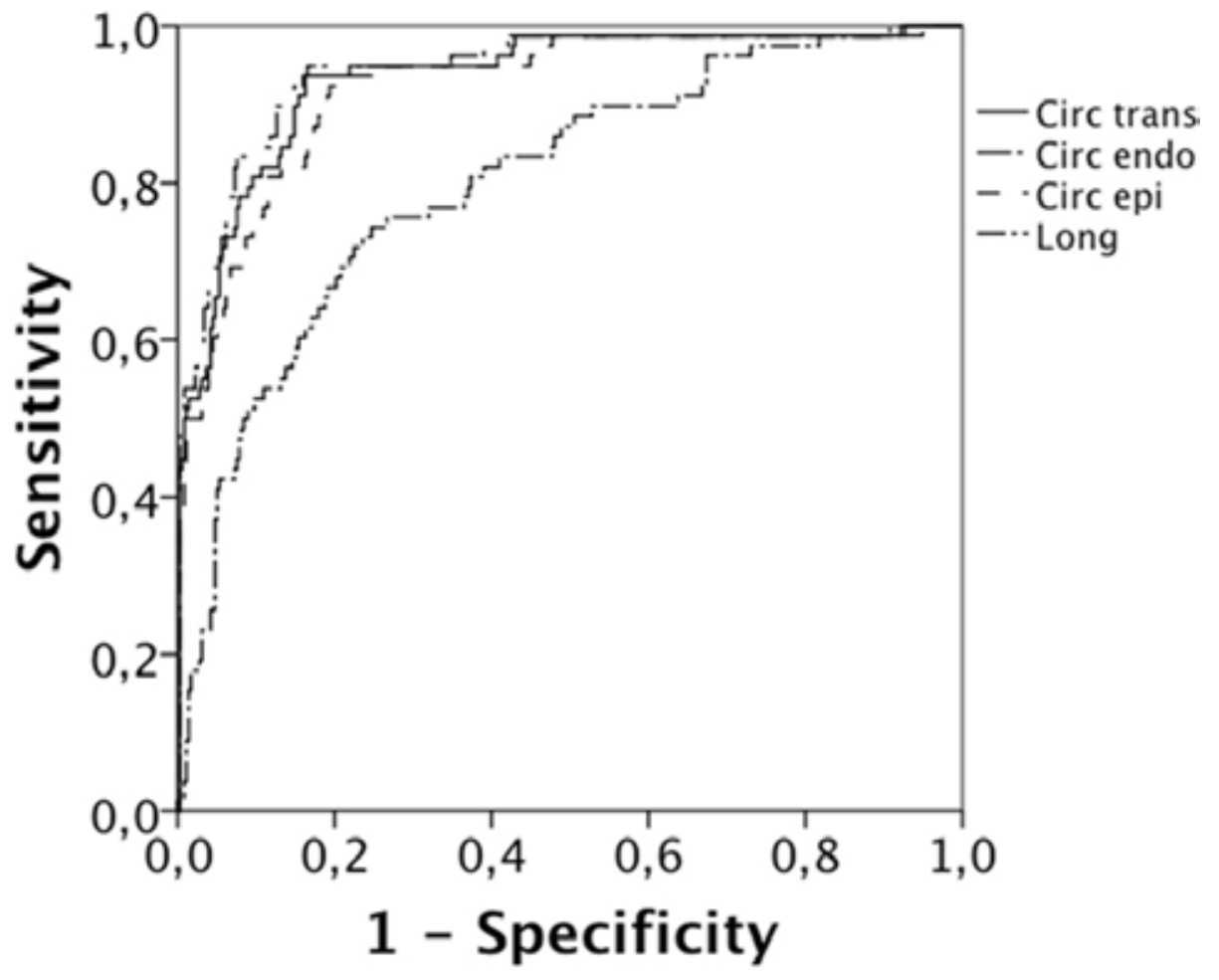

Figure 11. Receiver-operator characteristic curve for detecting $>50 \%$ LGE when using circumferential (circ) and longitudinal (long) strain. Circumferential strain is divided into subendocardial (endo), subepicardial (epi), and transmural (trans) layers.

The largest AUC was 0.92-0.94 for circumferential strain. The highest sensitivity at $80 \%$ specificity was that for subendocardial circumferential strain (94\%), closely followed by that for transmural circumferential strain (91\%), as shown in Table 1.

\begin{tabular}{lcccccc}
\hline Direction and layer of strain & AUC & $\begin{array}{c}\text { Sens (\%) at } \\
\text { spec } 80 \%\end{array}$ & $\begin{array}{c}\text { Cut-off } \\
\text { value (\%) }\end{array}$ & Scar (\%) & $\begin{array}{c}\text { Control } \\
\text { (\%) }\end{array}$ & p-value \\
\hline Radial subendocardial strain SA & 0.60 & 27 & N/A & $4 \pm 10$ & $9 \pm 11$ & 0.002 \\
Radial epicardial strain SA & 0.69 & 45 & N/A & $9 \pm 13$ & $19 \pm 14$ & $<0.001$ \\
Radial transmural strain SA & 0.66 & 39 & N/A & $7 \pm 11$ & $14 \pm 13$ & $<0.001$ \\
Radial transmural strain LA & 0.67 & 40 & N/A & $4 \pm 11$ & $12 \pm 13$ & $<0.001$ \\
Circumferential subendocardial strain & 0.94 & 95 & -17 & $-9 \pm 6$ & $-19 \pm 3$ & $<0.001$ \\
Circumferential epicardial strain & 0.92 & 91 & -14 & $-7 \pm 5$ & $-16 \pm 4$ & $<0.001$ \\
Circumferential transmural strain & 0.93 & 94 & -15 & $-8 \pm 5$ & $-17 \pm 4$ & $<0.001$ \\
Longitudinal transmural strain & 0.80 & 66 & -10 & $-7 \pm 7$ & $12 \pm 4$ & $<0.001$ \\
\hline
\end{tabular}

Table 1. Eighty segments with >50\% LGE (scarring) compared with 356 segments in the control group. The columns show the area under the curve (AUC) from the receiver-operator characteristics curve, sensitivity at $80 \%$ specificity, cut-off value for strain when applicable, 
and the mean strain and its standard deviation for the scar and control groups. SA, short axis; $L A$, long axis.

The control group had significant differences in radial strain, but not circumferential or longitudinal strain, among the basal, medial, and apical regions. The radial strain had a standard deviation (SD) around $50 \%$ of the measured strain value, while the longitudinal and circumferential strains had a much lower SD around $15 \%$ of the strain value.

There were significant differences in strain between the control group and the scar group for all three directions and both layers. The biggest difference with the smallest SD was for circumferential subendocardial strain, where the measured value for the control group was $-19 \%$ and that for the scar group was $-9 \%$.

The estimated cut-off values were $-10 \%$ and $-17 \%$ for longitudinal and circumferential strain, respectively, at the specificity level of $80 \%$. In the radial direction, sensitivity was below $50 \%$ when the specificity was $80 \%$.

Global circumferential strain (GCS) and global longitudinal strain (GLS) correlated significantly with LVEV. GCS showed less variance than GLS (Figure 12).
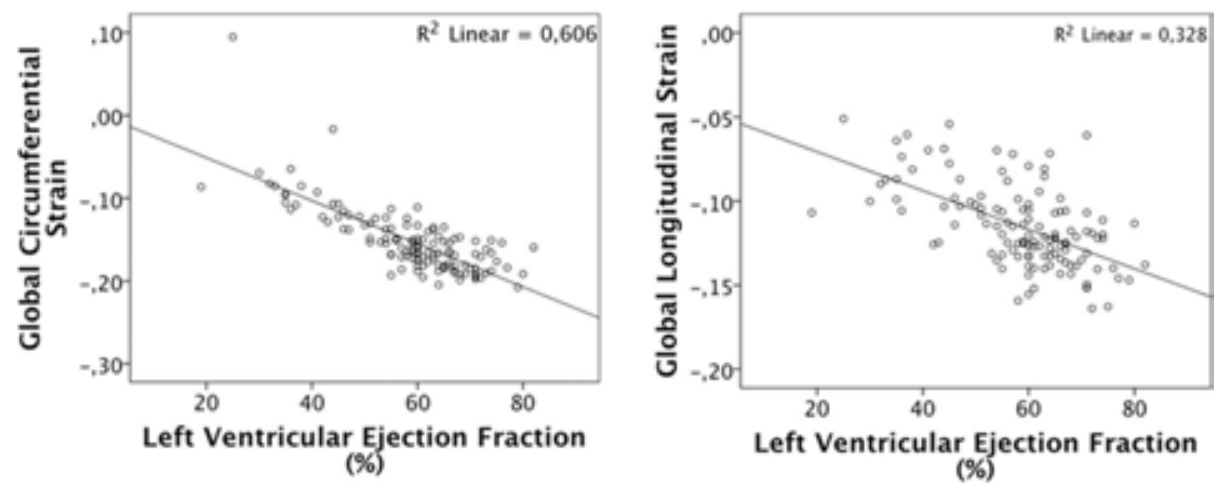

Figure 12. Correlation between global strain and left ventricle ejection fraction. The global strain is from the circumferential and longitudinal directions.

Reproducibility was excellent with an ICC of 0.93 for inter-observer variability and 0.95 for scan-re-scan variability.

\section{Paper 3}

All of the SSFP images were of good quality. Most (96\%) of the DENSE images had good quality, but $4 \%$ were affected by phase wrapping and could not be analyzed. The image quality of the FT images was good in $73 \%$ of the segments, acceptable in $19 \%$ of the segments, and too poor to analyze in $8 \%$ of the segments. 
GCS from DENSE and FT correlated strongly with the LVEF, while that from HARP showed a weaker correlation. The GCS from FT and DENSE also correlated significantly with LVESV, LVM, LV, LVEDV, and global LGE.

Segmental circumferential strain from DENSE and FT correlated with the segments that had LGE $>50 \%$ of the wall area per segment. The per-slice GCS correlated significantly with LGE, but that correlation was weaker than the per-segment correlation.

AUC analysis of the segments with LGE $>50 \%$ compared with the segments from patients without pathological findings showed that DENSE had the highest AUC (0.87), followed by HARP (o.68) and FT (0.56). Averaging over three timepoints improved the AUC of HARP strain from 0.56 to 0.67 but did not change the AUC of FT or DENSE strain.

\section{Paper 4}

Torsion measured by DENSE $\left(0.40^{\circ} / \mathrm{mm}\right)$ and HARP $\left(0.37^{\circ} / \mathrm{mm}\right)$ was significantly higher than that measured by FT $\left(0.17^{\circ} / \mathrm{mm}\right), \mathrm{p}<0.001$. The torsions from DENSE and HARP were not significantly different from each other.

The torsion from DENSE showed stronger correlations with LVM, LVEF, LVEDV, and LVESV than the torsion from HARP or FT. The torsion from HARP showed stronger correlations with those factors than the torsion from FT, see Table 2.

\begin{tabular}{lllll}
\hline Torsion & LVM & LVEF & LVEDV & LVESV \\
\hline DENSE & $-0.443^{* *}$ & $0.605^{* *}$ & $-0.479^{* *}$ & $-0.692^{* *}$ \\
HARP & $-0.339^{*}$ & 0.238 & $-0.375^{* *}$ & $-0.346^{*}$ \\
FT & -0.201 & 0.178 & -0.258 & -0.249 \\
FT_epi & $-0.391^{* *}$ & $0.326^{*}$ & $-0.416^{* *}$ & $-0.404^{* *}$ \\
FT_endo & -0.043 & 0.051 & -0.111 & -0.105 \\
\hline
\end{tabular}

Table 2. Pearson correlation factors between torsion derived from DENSE, HARP and FT and LVM, LVEF, LVEDV and LVESV. FT_epi represent FT from the epicardial boarder and $F T \_$endo the endocardial boarder. ${ }^{*}=p<0.05,{ }^{* * *}=p<0.01$.

The torsion in the epicardial layer measured by FT showed significant correlations with LVM, LVEF, LVEDV, and LVESV, although the correlation coefficients were moderately high. The epicardial torsion from FT showed higher correlation coefficients than that from HARP but HARP had still significant correlations with LVM, LVEDV, and LVESV. 


\section{DISCUSSION}

The focus of this thesis was to develop and evaluate improved CMR imaging techniques for patients with $\mathrm{CAD}$, especially techniques used to detect infarct scarring and to measure myocardial deformation. Early detection of disease leads to early treatment that can improve prognosis. The improved techniques can also be used in other cardiac diseases and as robust research tools.

\section{Aspects of the results}

\section{Paper 1}

To automate, simplify, and quantify the determination of an optimal inversion delay (TI), a sequence was modified and visualized using synthetic images developed in the SyMRI Cardiac Studio software. During one breath hold, almost the whole heart could be imaged and T1 quantified. However, the breath-hold duration was quite long (>20 s), depending on the heart rate and slice thickness. To produce complete coverage of larger hearts, the net slice distance would have to be increased to about $8 \mathrm{~mm}$ instead of $5 \mathrm{~mm}$ (thickness 10, distance -5 ).

The modified 3D PSIR sequence could reliably measure $\mathrm{T} 1$ relaxation within a broad range of T1 (200-800 ms). An optimal flip angle between 15 and 20 degrees produced a sufficiently high SNR with a stable T1. An inversion delay could be selected in the range of 300-600 ms without compromising T1, which is suitable for measuring LGE after the injection of Gd.

The sequence was investigated with respect to potential problems that could arise with arrhythmia. Arrhythmia, especially ventricular premature beats, are common in patients with CAD. The effect of short-lived changes in heart rate on the extrapolated T1 was smaller than that caused by the noise level, indicating that the sequence was robust enough to use with patients with arrhythmia.

Based on the projected T1 relaxation, an imperfect inversion pulse might cause an overestimation of T1. That effect could become a real risk at higher field strengths (e.g. 3 Tesla).

Using the 3D PSIR sequence, the T1 relaxation time in the LGE image was in the range of $200-500 \mathrm{~ms}$, which fits well with other studies $[54,140]$. 
The variation was rather wide because of differences in the time after contrast injection.

Because tissue voxels have several T1 compartments, the assumed monoexponential T1 decay was a simplification that could contribute to an imperfect correspondence with the reference sequence. Effects of chemical shift and the influence of compounds with very short T1 could also affect the relaxometry outcome. A further limitation was the property of the test tubes, which had a $\mathrm{T} 1$ relaxation up to $800 \mathrm{~ms}$; native myocardium has a T1 relaxation around $1100 \mathrm{~ms}$ with a range of 900-1300 ms [141, 142]. When just two readouts were used, the B1 inhomogeneities and the noise level could lead to too much instability above $800 \mathrm{~ms}$. The use of four readouts instead of two would minimize the influence of B1 inhomogeneities and noise. The addition of a T2-preperation prepulse could allow both $\mathrm{T} 1$ and $\mathrm{T} 2$ relaxation to be measured, as in the 3D QALAS sequence [143].

The comparisons between the experimental $3 \mathrm{D}$ PSIR post-processed images of scar and the reference 3D IR-TFE images showed similar extents of pathology, indicating that the 3D PSIR sequence can be used to support the choice of TI in the standard LGE sequence and can also be used by itself for LGE determination. For instance, in the thin wall of the right ventricle, the TIs may vary considerably compared with those in the LV wall [144]. If the LGE is acquired with the modified 3D PSIR sequence, it is possible to evaluate the presence of LGE using the different TIs that are present in the right ventricle and LV. That would create a better workflow for the operators, who could collect images at a specific TI that could be fine-tuned later for specific areas.

\section{Paper 2}

End-systolic strain was calculated in the radial, circumferential, and longitudinal directions based on three apical and three SA slices. Circumferential strain detected segments with LGE in $>50 \%$ of the segment area (transmurality) with a higher AUC than radial or longitudinal strain. Similar results have been presented by other authors using DENSE in suspected CAD [145] and in acute myocardial infarction [146]. Longitudinal strain is often used in echocardiography [65], because echo works well in apical views but not at all in SA views [46].

Cut-offs for circumferential and longitudinal strain were obtained that detected LGE in $>50 \%$ of the segment area with high sensitivity and specificity. Cut-offs for detecting disease are necessarily different from the normal reference range.

Mechanical considerations explain the higher levels of strain in the subendocardial layers compared with those in the subepicardial layers. That 
may contribute to the fact that the subendocardial layer had the highest sensitivity and AUC for detecting infarcted segments [147].

In the control group, the SD of the segmental strain amplitude was higher for the radial direction than for the circumferential and longitudinal directions. In the scar group, the SD exceeded the actual strain value. That can be understood in terms of a large variation in strain due to different extents of segmental scarring, but it could also be due, at least in part, to noisy measurements with low precision. Although there were significant differences between the scar and control groups, the AUC was small, preventing the use of radial strain for diagnostics. The high variability of radial strain in healthy individuals has also been demonstrated in other studies [148].

At the global level, there was a negative correlation between GCS and LVEF and between GLS and LVEF, but there was no such relationship for global radial strain. The same result has been found in patients with acute myocardial infarction [146].

The scan-rescan variability was in the same high range as the interobserver variability, which was based on repeated measurements on the same images. That result underscores the small influence of moving patients off the scanner table and emphasizes the robustness of strain acquisition using DENSE.

The control group was by definition not completely healthy, because the participants had been referred for myocardial scintigraphy; but the symptoms may have been due to reasons other than $\mathrm{CAD}$, and the investigations produced results that made heart disease unlikely. The control group had a similar gender and age distribution as the group with $>50 \%$ LGE, which makes their use as a reference population reasonable.

\section{Paper 3}

When comparing three different methods for measuring strain in a cohort of 90 patients, strain from DENSE showed the highest correlation with EF and LGE and could detect segments with LGE $>50 \%$ with high sensitivity and specificity. Previous comparisons have shown no difference in mean strain measurements between FT and DENSE [146], HARP and FT [23], and DENSE and HARP [149]. True differences may be concealed if comparisons are limited to mean values only, and correlation analysis may be more suited to detect differences between methods.

The image quality determines the accuracy of methods for determining strain. In this study, 100\% of the SSFP images were of good quality, which is similar to previous studies in which $95 \%$ of the scans were of high quali- 
ty [150]. Those studies used a single mid-ventricular slice, which might have concealed low image quality at the base and the apex, as has been shown for tagging $[151,152]$. The effects of reduced image quality at the basal and apical levels might have contributed to the failure of HARP analysis in $8 \%$ of the patients. Exclusion rates up to $10 \%$ have been reported for HARP post processing [153]. The reason for the underestimation of rotation by FT is unclear, but one hypothesis is that inferior tracking, whether in the circumferential direction or due to excessive throughplane motion, may have contributed to the observed difference.

\section{Paper 4}

The mean values of transmural torsion measured by DENSE and HARP were similar (0.40 degrees $/ \mathrm{mm}$ and 0.37 degrees $/ \mathrm{mm}$, respectively). For the 11 patients without pathological signs, those values were 0.39 degrees $/ \mathrm{mm}$ and 0.33 degrees $/ \mathrm{mm}$, respectively, which are similar to the values from recent studies of healthy volunteers [HARP: 0.37 degrees/mm [154]; DENSE: 0.34 degrees/mm [155]]. The mean torsion measured by FT among the 11 control patients was 0.22 degrees $/ \mathrm{mm}$, which is the same as the result of a previous FT study that measured it to be 0.23 degrees $/ \mathrm{mm}$ [135]. Those results suggest that the measurements obtained in this study are valid.

Torsion from HARP had a weaker correlation with LVEF, LVM, and LV volumes than torsion from FT in the epicardial layer and especially torsion from DENSE. It was shown previously that strain from HARP has a relatively low reproducibility in the basal and apical regions [151, 152]. That problem could be related to partial volume effects, especially exaggerated displacement in the radial direction in apical segments and in the longitudinal direction in basal segments. Even if those mechanisms were not studied, there could be reason to believe that they also affect torsion from HARP.

Torsion from epicardial FT showed stronger correlations with LVM, LVEF, and LV volumes than torsion from transmural FT or subendocardial FT. Because transmural FT is calculated as the mean of subendocardial FT and subepicardial FT, the transmural result depends on how much the measured epicardial rotation is diluted by the less-accurate measurement of subendocardial rotation. The tracking of the epicardial contour might have been better because of the absence of trabeculae and a smaller impact of through-plane motion.

Paper 4 included fewer patients than Paper 3, which restricted the analysis in the former. The requirement for high-quality recordings using all three methods caused many exclusions, which was the reason that only correlations with LVEF or infarct size could be analyzed. The interest was to determine end-systolic torsion, but there was a restriction to recording 
three time frames. Similar timepoints were extracted for all three techniques, but HARP and FT had the added advantage of allowing analysis of the entire heartbeat (cine). By restricting the DENSE sequence to three time frames, the SNR was improved, resulting in a higher resolution that might have provided an advantage in the comparison with the other two techniques. It is feasible, however, to acquire more time points with the DENSE sequence [156]. Another limitation to the comparison in Paper 4 is that only transmural torsion was calculated from DENSE and HARP measurements because of limitations in the software. A more detailed comparison of the merits of transmural strain measurements compared with endocardial strain measurements seems to be warranted.

\section{Methodological considerations}

To develop an MRI examination method, extensive tests are required before patients are involved. For the T1 mapping method "synthetic MRI," the tests started with phantoms followed by mathematical simulations of the proposed changes to the conventional 3D PSIR sequence. The potential influences of magnetic field interactions, energy absorption, and various properties of relaxation had to be tested in vivo; however, simulations can reduce the number of physical experiments required. Monte Carlo simulation is an effective technique to study potential interactions of multiple parameters related to the noise level. Paper 1 was focused on the extrapolation of the T1 relaxation curve and the factors that are important to control in order to produce a reliable extrapolation. The paper focused on the development of the sequence; a formal comparison of the image content and quality between the extrapolated, "synthetic" images and the standard LGE images was beyond the scope of the article. Such a comparison is difficult, because different readers of CMR may have different criteria for good image quality. Efforts to resolve such differences might benefit from the use of tools such as Likert scales.

When it was correlated with other expressions of cardiovascular disease, the DENSE sequence showed superior performance compared with the reference HARP tagging technique. In this study, HARP underperformed compared with its performance in some previous publications; however, even in a comparison with data from the literature, DENSE appears to have clear advantages for determining strain amplitude and torsion. When applied to patients, the use of DENSE in post-infarct imaging may improve prognostic evaluation.

The clinical characteristics of patients and the definition of the reference population determine what results can be achieved. Ideally, a reference population should be free from disease, but in real life, test patients are compared with healthy but similarly aged patients living under similar 
conditions, which supports the definition of the reference population used here.

All of the included patients had stable symptoms. Although none of the patients were in an unstable condition or experiencing the development of an acute myocardial infarction, the tools used here to assess cardiac function will also be attractive for application in the immediate post-infarct period.

Previous studies have shown some advantages based on the use of core labs for analysis. Those results are related to the expertise of the core labs. The process of anonymizing and sending data may result in the loss of data, however. There was such an experience with the tagging data, as $24 \%$ of the included tagging studies were lost in the central database and never sent out for core lab analysis.

\section{Statistical analyses}

Papers 3-4 showed the advantages of DENSE in relation to other measures of cardiac function. All methods have variability related to repeatability, random errors, and biological variation. Therefore, it is important to study the reproducibility of the acquisition from a scan-rescan point of view as well as from interobserver measurements on identical images. Several methods to measure variability; such as the coefficient of variation, ICC, and limits of agreement; have been used over the years. ICC was selected, which is centered and scaled and uses pooled mean and variance. The reported value, between 0 and 1 , indicates the proportion of the variance of an observation that is due to the variance among subjects. ICC is close to 1 if there is a small variation among the values. With the limits of agreement according to Bland and Altman [157], the variance is plotted against the means of the measurements, representing one of the most common methods to measure the reliability [158]. ROC curves allow the calculation of a cut-off value that can be characterized in terms of the sensitivity and specificity for determining the presence or absence of disease. That can be done numerically (e.g. Youden's index) to get the highest possible sensitivity with the highest possible specificity. It is common, however, to use a fixed specificity value of $80 \%$, which allows an easier comparison between methods.

\section{General discussion}

Our modification of $3 \mathrm{D}$ PSIR with post processing worked well to measure myocardial T1 relaxation up to $800 \mathrm{~ms}$; however, native T1 frequently exceeds $1000 \mathrm{~ms}$, which makes the method best suited to the study of tissue after the injection of Gd contrast, when T1 shortens to about $400 \mathrm{~ms}$. Based on the experience from this thesis, another sequence, 3D QALAS, was developed [143]. That sequence can determine T1 as well as T2 relax- 
ation in the myocardium with extensive coverage within a single breath hold. The MRI community has proposed a pathway to resolve differences in nomenclature, phantom standards, reporting, and the administration of contrast media [55]. The 3D PSIR technique may fall short in some aspects, such as the measurement of native T1, but may be helpful in setting the TI for other LGE sequences and in special conditions such as amyloidosis, where the correct TI is exceedingly difficult to determine.

All of the patients that underwent DENSE analysis had a high likelihood of $\mathrm{CAD}$, even if a subpopulation was considered fairly healthy after review. DENSE was able to measure strain and torsion with high precision in all of the normal and pathophysiological conditions tested. Compared with the LVEF, the standard measure of cardiac systolic function, strain analysis including torsion seems to be able to pick up earlier disease states. Because strain and torsion are separate and individual variations of the complex 3D strain tensor [159], a combination of torsion and global strain amplitude may reflect pump function better than other methods.

There is a need for standardization of the way torsion is defined and measured [95]. Such standardization is necessary to allow the use of DENSE strain and torsion to analyze changes in cardiac function in largescale intervention studies.

The early detection of disease based on DENSE strain and torsion could allow early preventive treatment and the monitoring of disease progression. The response to such early therapy would help to facilitate the creation of truly personalized medical care. Furthermore, providing patients feedback on cardiac function based on strain and torsion could enhance patient compliance in situations requiring regular medication.

Presently, strain is expressed as segmental values and as a global value dependent on six slices of 16 segments (entire heart). The next step in the development of strain assessment could be the mapping of strain tensors pixel by pixel, which would better demonstrate the spatial distribution of disease and could possibly be applied to various studies of prognosis after major events, such as myocardial infarction [160]. Currently, there are several competing techniques that describe various aspects of cardiac function. New "deep learning" analyses of complicated interactions might disclose relationships that will improve the identification of remodeling, ultimately reducing the progression of cardiac dysfunction into overt heart failure. 
Magnetic Resonance Imaging of Myocardial Deformation and Scarring in Coronary Artery Disease. 


\section{CONCLUSIONS}

The conclusions from the four papers included in this thesis are the following:

-Quantification of $\mathrm{T} 1$ is possible using the 3D PSIR LGE method and synthetic MRI postprocessing.

-A modified DENSE strain analysis can detect myocardial scarring with high sensitivity and specificity in patients with CAD.

-Strain amplitude determined with DENSE correlates better with global measurements of cardiac anatomy and function than strain determined with HARP or FT. Strain from DENSE detects major myocardial infarction with higher accuracy than strain from HARP or FT.

-Torsion from DENSE correlates better with global measurements of cardiac anatomy and function in patients with CAD than other deformation-based methods such as torsion from HARP or FT. 
Magnetic Resonance Imaging of Myocardial Deformation and Scarring in Coronary Artery Disease. 


\section{REFERENCES}

1. Carlsson, M., et al., Total heart volume variation throughout the cardiac cycle in humans. American Journal of Physiology - Heart and Circulatory Physiology, 2004. 287(1): p. H243-H250.

2. Greenbaum, R.A., et al., Left ventricular fibre architecture in man. British Heart Journal, 1981. 45(3): p. 248-263.

3. Ingels, J.N.B., Myocardial fiber architecture and left ventricular function. Technology \& Health Care, 1997. 5(1/2): p. 45.

4. Rushmer, R.F., D.K. Crystal, and C. Wagner, The Functional Anatomy of Ventricular Contraction. Circulation Research, 1953. 1(2): p. 162-170.

5. Torrent-Guasp, F., et al., Spatial orientation of the ventricular muscle band: physiologic contribution and surgical implications. J Thorac Cardiovasc Surg, 2001. 122(2): p. 38992.

6. Buckberg, G.D., et al., MRI myocardial motion and fiber tracking: a confirmation of knowledge from different imaging modalities. Eur J Cardiothorac Surg, 2006. 29.

7. Croisille, P., et al., Differentiation of Viable and Nonviable Myocardium by the Use of Three-Dimensional Tagged MRI in 2-Day-Old Reperfused Canine Infarcts. Circulation, 1999. 99(2): p. 284-291.

8. Arts, T., R.S. Reneman, and P.C. Veenstra, A model of the mechanics of the left ventricle. Annals of biomedical engineering, 1979. 7(3-4): p. 299-318.

9. Benjamin, E.J., et al., Heart Disease and Stroke Statistics-2017 Update: A Report From the American Heart Association. Circulation, 2017. 135(10): p. e146-e603.

10. Johansson, P., et al., Global perceived health and health-related quality of life in elderly primary care patients with symptoms of heart failure. European Journal of Cardiovascular Nursing, 2008. 7(4): p. 269-276.

11. Hunt, S.A., et al., ACC/AHA guidelines for the evaluation and management of chronic heart failure in the adult: executive summary: A report of the american college of cardiology/american heart association task force on practice guidelines (committee to revise the 1995 guidelines for the evaluation and management of heart failure) developed in collaboration with the international society for heart and lung transplantation endorsed by the heart failure society of america. J Am Coll Cardiol, 2001. 38(7): p. 2101-2113.

12. Jonsson, B.W., Per, Klinisk fysiologi med nuklearmedicin och klinisk neurofysiologi. 2006, Stockholm: Liber.

13. Nesto, R.W. and G.J. Kowalchuk, The ischemic cascade: Temporal sequence of hemodynamic, electrocardiographic and symptomatic expressions of ischemia. The American Journal of Cardiology, 1987. 59(7): p. C23-C30.

14. Naghavi, M., et al., From Vulnerable Plaque to Vulnerable Patient, A Call for New Definitions and Risk Assessment Strategies: Part I. Circulation Journal, 2003. 108(14): p. 1664-1672.

15. Ghoshhajra, B.B., R.C. Cury, and R.D. White, Chapter 20. Ischemic Heart Disease, in Multimodal Cardiovascular Imaging: Principles and Clinical Applications, O. Pahlm and G.S. Wagner, Editors. 2011, The McGraw-Hill Companies: New York, NY.

16. Aurigemma, G.P., Diastolic Heart Failure - A Common and Lethal Condition by Any Name. New England Journal of Medicine, 2006. 355(3): p. 308-310. 
17. Aurigemma, G.P., M.R. Zile, and W.H. Gaasch, Contractile Behavior of the Left Ventricle in Diastolic Heart Failure. With Emphasis on Regional Systolic Function, 2006. 113(2): p. 296-304.

18. Ugander, M., Dysfunctional but viable myocardium-Ischemic heart disease assessed by magnetic resonance imaging and single photon emission computed tomography, in Faculty of Medicine 2005, Lund University: Lund.

19. Sylvén, C., Mechanisms of pain in angina pectoris-A critical review of the adenosine hypothesis. Cardiovascular Drugs and Therapy, 1993. 7(5): p. 745-759.

20. Braunwald, E. and R.A. Kloner, The stunned myocardium: prolonged, postischemic ventricular dysfunction. Circulation, 1982. 66(6): p. 1146-1149.

21. Sanz, G., et al., Determinants of Prognosis in Survivors of Myocardial Infarction. New England Journal of Medicine, 1982. 306(18): p. 1065-1070.

22. Kim, R.J., et al., Relationship of MRI Delayed Contrast Enhancement to Irreversible Injury, Infarct Age, and Contractile Function. Circulation, 1999. 100(19): p. 1992-2002.

23. Kelle, S., et al., Prognostic Value of Myocardial Infarct Size and Contractile Reserve Using Magnetic Resonance Imaging. Journal of the American College of Cardiology, 2009. 54(19): p. 1770-1777.

24. Westbrook, C., MRI at a Glance. 2002: Wiley.

25. McRobbie, D.W., et al., MRI from Picture to Proton. 2010: Cambridge university press.

26. Westbrook, C. and C.K. Roth, MRI in Practice. 1998: Wiley.

27. Liney, G., MRI in Clinical Practice. 2006: Springer.

28. Abildgaard, A., MR for radiografer og radiologer: fysikk og fysiologi. 2016: Universitetsforl.

29. Hammer, M. MRI Physics: Pulse Sequences. 2014 [cited 2017 September 2]; Available from: http://xrayphysics.com/se diag wgrad.png.

30. Panych, L.P. and B. Madore, The physics of MRI safety. Journal of Magnetic Resonance Imaging, 2017.

31. Machata, A.M., et al., Effect of brain magnetic resonance imaging on body core temperature in sedated infants and children. BJA: British Journal of Anaesthesia, 2009. 102(3): p. 385-389.

32. Price, D.L., et al., Investigation of acoustic noise on $15 \mathrm{MRI}$ scanners from $0.2 \mathrm{~T}$ to $3 \mathrm{~T}$. Journal of magnetic resonance imaging, 2001. 13(2): p. 288-293.

33. Elmaoglu, M. and A. Çelik, MRI handbook. [Elektronisk resurs] : MR physics, patient positioning, and protocols. 2012: New York, NY : Springer, c2012.

34. Theysohn, J.M., et al., Vestibular effects of a 7 Tes/a MRI examination compared to 1.5 $T$ and $O T$ in healthy volunteers. PloS one, 2014. 9(3): p. e92104.

35. Rinck, P.A., Magnetic Resonance in Medicine: The Basic Textbook of the European Magnetic Resonance Forum. 1993: Blackwell Scientific Publications.

36. Shellock, F. MRI Safety. 2017 [cited 201721 September]; Available from: http://www.mrisafety.com/.

37. ADMINISTRATION, U.S.F.A.D. MRI Safety: FDA Safety Communication. 20142014 October 06; Available from:

https://www.fda.gov/medicaldevices/safety/alertsandnotices/ucm135362.htm.

38. Fraum, T.J., et al., Gadolinium - based contrast agents: A comprehensive risk assessment. Journal of Magnetic Resonance Imaging, 2017.

39. European Medicines Agency. EMA's final opinion confirms restrictions on use of linear gadolinium agents in body scans. 201721 July 2017; Available from:

http://www.ema.europa.eu/docs/en GB/document library/Referrals document/gad olinium contrast agents 31/Opinion provided by Committee for Medicinal Produ cts for Human Use/WC500231824.pdf.

40. Ray, J.G., et al., Association between MRI exposure during pregnancy and fetal and childhood outcomes. Jama, 2016. 316(9): p. 952-961. 
41. Vårdguiden. Magnetkameraundersökning. 201618 April 2016; Available from: https://www.1177.se/Ostergotland/Fakta-ochrad/Undersokningar/Magnetkameraundersokning/.

42. Kramer, C.M., et al., Standardized cardiovascular magnetic resonance (CMR) protocols 2013 update. Journal of Cardiovascular Magnetic Resonance, 2013. 15(1): p. 91.

43. Schwitter, J., CMR-update. 2012: Juerg Schwitter, MD, FESC. Lausanne, Switerland.

44. Suinesiaputra, A., et al., Quantification of LV function and mass by cardiovascular magnetic resonance: multi-center variability and consensus contours. J Cardiovasc Magn Reson, 2015. 17.

45. Patel, H., et al., Myocardial viability-State of the art: Is it still relevant and how to best assess it with imaging? Trends in Cardiovascular Medicine, 2017.

46. Pedrizzetti, G., et al., Principles of cardiovascular magnetic resonance feature tracking and echocardiographic speckle tracking for informed clinical use. Journal of Cardiovascular Magnetic Resonance, 2016. 18(1): p. 51.

47. Fratz, S., et al., Guidelines and protocols for cardiovascular magnetic resonance in children and adults with congenital heart disease: SCMR expert consensus group on congenital heart disease. Journal of Cardiovascular Magnetic Resonance, 2013. 15(1): p. 1-26.

48. Schulz-Menger, J., et al., Standardized image interpretation and post processing in cardiovascular magnetic resonance: Society for Cardiovascular Magnetic Resonance (SCMR) board of trustees task force on standardized post processing. Journal of Cardiovascular Magnetic Resonance, 2013. 15(1): p. 35.

49. Dyverfeldt, P., et al., 4D flow cardiovascular magnetic resonance consensus statement. Journal of Cardiovascular Magnetic Resonance, 2015. 17(1): p. 72.

50. Dyverfeldt, P., et al., Quantification of intravoxel velocity standard deviation and turbulence intensity by generalizing phase - contrast MRI. Magnetic resonance in medicine, 2006. 56(4): p. 850-858.

51. Dyverfeldt, P., et al., Magnetic resonance measurement of turbulent kinetic energy for the estimation of irreversible pressure loss in aortic stenosis. JACC: Cardiovascular Imaging, 2013. 6(1): p. 64-71.

52. Anderson, L., et al., Cardiovascular T2-star $\left(T 2^{*}\right)$ magnetic resonance for the early diagnosis of myocardial iron overload. European heart journal, 2001. 22(23): p. 21712179.

53. Taher, A., C. Hershko, and M.D. Cappellini, Iron overload in thalassaemia intermedia: reassessment of iron chelation strategies. British journal of haematology, 2009. 147(5): p. 634-640.

54. Flett, A.S., et al., Equilibrium contrast cardiovascular magnetic resonance for the measurement of diffuse myocardial fibrosis. Circulation, 2010. 122(2): p. 138-144.

55. Moon, J.C., et al., Myocardial T1 mapping and extracellular volume quantification: a Society for Cardiovascular Magnetic Resonance (SCMR) and CMR Working Group of the European Society of Cardiology consensus statement. Journal of Cardiovascular Magnetic Resonance, 2013. 15(1): p. 92.

56. Schwitter, J., et al., MR-IMPACT II: Magnetic Resonance Imaging for Myocardial Perfusion Assessment in Coronary artery disease Trial: perfusion-cardiac magnetic resonance vs. single-photon emission computed tomography for the detection of coronary artery disease: a comparative... 2012.

57. Kozerke, S., et al., Volume tracking cardiac 31P spectroscopy. Magnetic resonance in medicine, 2002. 48(2): p. 380-384.

58. Kellman, P. and A.E. Arai, Cardiac imaging techniques for physicians: late enhancement. Journal of magnetic resonance imaging, 2012. 36(3): p. 529-542. 
59. Amundsen, B.H., et al., Noninvasive myocardial strain measurement by speckle tracking echocardiography: validation against sonomicrometry and tagged magnetic resonance imaging. J Am Coll Cardiol, 2006. 47.

60. Mor-Avi, V., et al., Current and evolving echocardiographic techniques for the quantitative evaluation of cardiac mechanics: ASE/EAE consensus statement on methodology and indications endorsed by the Japanese Society of Echocardiography. European Journal of Echocardiography, 2011. 12(3): p. 167-205.

61. Singh, G.K., et al., Accuracy and Reproducibility of Strain by Speckle Tracking in Pediatric Subjects with Normal Heart and Single Ventricular Physiology: A TwoDimensional Speckle-Tracking Echocardiography and Magnetic Resonance Imaging Correlative Study. Journal of the American Society of Echocardiography, 2010. 23(11): p. $1143-1152$.

62. Waldman, L.K., et al., Relation between transmural deformation and local myofiber direction in canine left ventricle. Circ Res, 1988. 63.

63. MIRSKY, I. and W.W. PARMLEY, Assessment of Passive Elastic Stiffness for Isolated Heart Muscle and the Intact Heart. Circulation Research, 1973. 33(2): p. 233-243.

64. Simpson, R.M., J. Keegan, and D.N. Firmin, MR assessment of regional myocardial mechanics. Journal of Magnetic Resonance Imaging, 2013. 37(3): p. 576-599.

65. Urheim, S., et al., Myocardial Strain by Doppler Echocardiography: Validation of a New Method to Quantify Regional Myocardial Function. Circulation, 2000. 102(10): p. 11581164.

66. Reisner, S.A., et al., Global longitudinal strain: a novel index of left ventricular systolic function. J Am Soc Echocardiogr, 2004. 17.

67. Axel, L. and L. Dougherty, MR imaging of motion with spatial modulation of magnetization. Radiology, 1989. 171.

68. Osman, N.F., et al., Cardiac motion tracking using CINE harmonic phase (HARP) magnetic resonance imaging. Magn Reson Med, 1999. 42(6): p. 1048-60.

69. Ibrahim, E.-S., Myocardial tagging by Cardiovascular Magnetic Resonance: evolution of techniques--pulse sequences, analysis algorithms, and applications. Journal of Cardiovascular Magnetic Resonance, 2011. 13(1): p. 36.

70. Young, A.A., et al., Generalized spatiotemporal myocardial strain analysis for DENSE and SPAMM imaging. Magnetic Resonance in Medicine, 2012. 67(6): p. 1590-1599.

71. Zhu, Y., M. Drangova, and N.J. Pelc, Estimation of deformation gradient and strain from cine-PC velocity data [cardiac magnetic resonance imaging]. IEEE transactions on medical imaging, 1997. 16(6): p. 840-851.

72. Haraldsson, H., et al., Improved estimation and visualization of two - dimensional myocardial strain rate using $M R$ velocity mapping. Journal of magnetic resonance imaging, 2008. 28(3): p. 604-611.

73. Chitiboi, T., et al., Analyzing myocardial torsion based on tissue phase mapping cardiovascular magnetic resonance. Journal of Cardiovascular Magnetic Resonance, 2016. 18(1): p. 15.

74. Codreanu, I., et al., Longitudinally and circumferentially directed movements of the left ventricle studied by cardiovascular magnetic resonance phase contrast velocity mapping. Journal of Cardiovascular Magnetic Resonance, 2010. 12(1): p. 1-8.

75. Osman, N.F., et al., Imaging longitudinal cardiac strain on short-axis images using strain-encoded MRI. Magnetic Resonance in Medicine, 2001. 46(2): p. 324-334.

76. Kawaji, K., A Single Breath-Hold Simultaneous Acquisition Approach of Both Cine-CMR and Strain-Encoded CMR for a Combined Assessment of Myocardial Wall Motion, in SCMR 2017. 2017: Washington, USA.

77. Ibrahim, E.S.H., et al., Combined functional and viability cardiac MR imaging in a single breathhold. Magnetic resonance in medicine, 2007. 58(4): p. 843-849. 
78. Aletras, A.H., et al., DENSE: Displacement Encoding with Stimulated Echoes in Cardiac Functional MRI. Journal of Magnetic Resonance, 1999. 137(1): p. 247-252.

79. Kim, D., et al., Myocardial tissue tracking with two-dimensional cine displacementencoded MR imaging: development and initial evaluation. Radiology, 2004. 230: p. 862 $-871$.

80. Herzka, D.A. and E.R. McVeigh, MRI of myocardial infarction with tissue tagging. Current Cardiovascular Imaging Reports, 2009. 2(1): p. 73.

81. Maret, E., et al., Functional measurements based on feature tracking of cine magnetic resonance images identify left ventricular segments with myocardial scar. Cardiovasc Ultrasound, 2009. 7: p. 53.

82. Rüssel, I.K., et al., Left Ventricular Torsion. JACC: Cardiovascular Imaging, 2009. 2(5): p. 648.

83. Esch, B.T. and D.E.R. Warburton, Left ventricular torsion and recoil: implications for exercise performance and cardiovascular disease. Journal of Applied Physiology, 2009. 106(2): p. 362-369.

84. Fonseca, C.G., et al., Aging alters patterns of regional nonuniformity in LV strain relaxation: a 3-D MR tissue tagging study. Am J Physiol Heart Circ Physiol, 2003. 285.

85. Oxenham, H.C., et al., Age-Related Changes in Myocardial Relaxation Using ThreeDimensional Tagged Magnetic Resonance Imaging. Journal of Cardiovascular Magnetic Resonance, 2003. 5(3): p. 421-430.

86. Yoneyama, K., et al., Age, sex, and hypertension-related remodeling influences left ventricular torsion assessed by tagged cardiac magnetic resonance in asymptomatic individuals: the multi-ethnic study of atherosclerosis. Circulation, 2012. 126.

87. Kim, C.S., S. Park, and L.Y. Eun, Myocardial rotation and torsion in child growth. Journal of cardiovascular ultrasound, 2016. 24(3): p. 223-228.

88. Ahmed, M.I., et al., Relation of Torsion and Myocardial Strains to LV Ejection Fraction in Hypertension. JACC: Cardiovascular Imaging, 2012. 5(3): p. 273-281.

89. Russel, I.K., et al., Increased left ventricular torsion in hypertrophic cardiomyopathy mutation carriers with normal wall thickness. J Cardiovasc Magn Reson, 2011. 13.

90. Kramer, S.P., et al., Obesity reduces left ventricular strains, torsion, and synchrony in mouse models: a cine displacement encoding with stimulated echoes (DENSE) cardiovascular magnetic resonance study. Journal of Cardiovascular Magnetic Resonance, 2013. 15(1): p. 109.

91. Buchalter, M.B., et al., Rotational deformation of the canine left ventricle measured by magnetic resonance tagging: effects of catecholamines, ischaemia, and pacing. Cardiovasc Res, 1994. 28.

92. Nagel, E.S., M; Lakatos, M; Scheidegger,M; Boesiger, P; Hess, O, Cardiac rotation and relaxation after anterolateral myocardial infarction. Coronary Artery Disease, 2000.

93. Takeuchi, M., et al., The assessment of left ventricular twist in anterior wall myocardial infarction using two-dimensional speckle tracking imaging. J Am Soc Echocardiogr, 2007. 20.

94. Henson, R.E., et al., Left ventricular torsion is equal in mice and humans. American Journal of Physiology - Heart and Circulatory Physiology, 2000. 278(4): p. H1117$\mathrm{H} 1123$.

95. Young, A.A. and B.R. Cowan, Evaluation of left ventricular torsion by cardiovascular magnetic resonance. Journal of Cardiovascular Magnetic Resonance, 2012. 14(1): p. 49.

96. Quirk, M.E., et al., Anxiety in patients undergoing MR imaging. Radiology, 1989. 170(2): p. 463-466.

97. Katz, R.C., L. Wilson, and N. Frazer, Anxiety and its determinants in patients undergoing Magnetic Resonance Imaging. Journal of Behavior Therapy and Experimental Psychiatry, 1994. 25(2): p. 131-134. 
98. Mclsaac, H.K., et al., Claustrophobia and the Magnetic Resonance Imaging Procedure. Journal of Behavioral Medicine, 1998. 21(3): p. 255-268.

99. Tischler, V., et al., Patient anxiety in magnetic resonance imaging centres: is further intervention needed? Radiography, 2008. 14(3): p. 265-266.

100. Murphy, F., Understanding the humanistic interaction with medical imaging technology. Radiography, 2001. 7(3): p. 193-201.

101. Thorpe, S., P.M. Salkovskis, and A. Dittner, Claustrophobia in MRI: the role of cognitions. Magnetic Resonance Imaging, 2008. 26(8): p. 1081-1088.

102. Munn, Z. and Z. Jordan, The patient experience of high technology medical imaging: $A$ systematic review of the qualitative evidence. Radiography, 2011. 17(4): p. 323-331.

103. Kihlberg, J., Patientnöjdhet vid tre röntgenkliniker, in Faculty of Medicine and Health Sciences, Division of Nursing Science. 2003, Linköping University: Linköping.

104. Ollivier, L., et al., Patient experiences and preferences: development of practice guidelines in a cancer imaging department. Cancer Imaging, 2009. 9(Special issue A): p. S92.

105. Lundvall, L.-L., M.A. Dahlgren, and S. Wirell, Professionals' experiences of imaging in the radiography process-A phenomenological approach. Radiography, 2014. 20(1): $p$. 48-52.

106. Törnqvist, E., et al., Impact of Extended Written Information on Patient Anxiety and Image Motion Artifacts During Magnetic Resonance Imaging. Acta Radiologica, 2006. 47(5): p. 474-480.

107. Ahlander, B.M., Magnetic Resonance Imaging of the Heart; Image quality, measurement accuracy and patient experience, in Faculty of Medicine and Health Sciences. 2016, Linköping University: Linköping.

108. Powell, R., et al., Improving magnetic resonance imaging (MRI) examinations: Development and evaluation of an intervention to reduce movement in scanners and facilitate scan completion. British Journal of Health Psychology, 2015. 20(3): p. 449465.

109. Selim, M., Effect of pre-instruction on anxiety levels of patients undergoing magnetic resonance imaging examination. Eastern Mediterranean Health Journal 2001. 7(3): p. 519-525.

110. Grey, S.J., G. Price, and A. Mathews, Reduction of anxiety during MR imaging: a controlled trial. Magnetic Resonance Imaging, 2000. 18(3): p. 351-355.

111. Munn, Z. and Z. Jordan, Interventions to reduce anxiety, distress and the need for sedation in adult patients undergoing magnetic resonance imaging: a systematic review. International Journal of Evidence-Based Healthcare, 2013. 11(4): p. 265-274.

112. Carlsson, S. and E. Carlsson, 'The situation and the uncertainty about the coming result scared me but interaction with the radiographers helped me through': a qualitative study on patients' experiences of magnetic resonance imaging examinations. Journal of Clinical Nursing, 2013. 22(21-22): p. 3225-3234.

113. Tazegul, G., et al., Can MRI related patient anxiety be prevented? Magnetic Resonance Imaging, 2015. 33(1): p. 180-183.

114. Öst, L.G., et al., One vs five sessions of exposure and five sessions of cognitive therapy in the treatment of claustrophobia. Behaviour Research and Therapy, 2001. 39(2): p. 167-183.

115. Enders, J., et al., Reduction of Claustrophobia with Short-Bore versus Open Magnetic Resonance Imaging: A Randomized Controlled Trial. PLOS ONE, 2011. 6(8): p. e23494.

116. Dewey, M., T. Schink, and C.F. Dewey, Claustrophobia during magnetic resonance imaging: Cohort study in over 55,000 patients. Journal of Magnetic Resonance Imaging, 2007. 26(5): p. 1322-1327. 
117. Bangard, C., et al., MR imaging of claustrophobic patients in an open 1.0 T scanner: motion artifacts and patient acceptability compared with closed bore magnets. European journal of radiology, 2007. 64(1): p. 152-157.

118. Törnqvist, E., et al., It's like being in another world-patients' lived experience of magnetic resonance imaging. Journal of clinical nursing, 2006. 15(8): p. 954-961.

119. Funk, E., P. Thunberg, and A. Anderzen - Carlsson, Patients' experiences in magnetic resonance imaging (MRI) and their experiences of breath holding techniques. Journal of advanced nursing, 2014. 70(8): p. 1880-1890.

120. Hamlet, S.M., et al., An interactive videogame designed to improve respiratory navigator efficiency in children undergoing cardiac magnetic resonance. J Cardiovasc Magn Reson, 2016. 18.

121. Hutton, J., et al., Psychological impact and acceptability of magnetic resonance imaging and X-ray mammography: the MARIBS Study. Br J Cancer, 2011. 104(4): p. 578-586.

122. Lundén, M., S.M. Lundgren, and M. Lepp, The nurse radiographers' experience of meeting with patients during interventional radiology. Journal of Radiology Nursing, 2012. 31(2): p. 53-61.

123. Författningssamling, S.-S., Lag (2003: 460) om etikprövning av forskning som avser människor. Stockholm: Utbildningsdepartementet, 2003.

124. World Medical, A., World medical association declaration of helsinki: Ethical principles for medical research involving human subjects. JAMA, 2013. 310(20): p. 2191-2194.

125. Tödt, T., et al., Relationship between treatment delay and final infarct size in STEMI patients treated with abciximab and primary PCI. BMC cardiovascular disorders, 2012. 12(1): p. 9.

126. Rademakers, F., et al., Determining optimal noninvasive parameters for the prediction of left ventricular remodeling in chronic ischemic patients. Scandinavian Cardiovascular Journal, 2013. 47(6): p. 329-334.

127. Kellman, P., et al., Phase - sensitive inversion recovery for detecting myocardial infarction using gadolinium - delayed hyperenhancement. Magnetic resonance in medicine, 2002. 47(2): p. 372-383

128. Zhong, X., P.A. Helm, and F.H. Epstein, Balanced multipoint displacement encoding for DENSE MRI. Magnetic Resonance in Medicine, 2009. 61(4): p. 981-988.

129. Tsao, J. and D. Laurent. N-SPAMM for efficient displacement-encoded acquisition in myocardial tagging. in Proceedings of the 13th Annual Meeting of ISMRM. 2005.

130. Takase, S., A. Sigfridsson, and H. Sakuma, Spiral DENSE with short breath hold duration, in ISMRM. 2011: Montreal, Canada.

131. Stuber, M., et al., Single breath-hold slice-following CSPAMM myocardial tagging. Magnetic Resonance Materials in Physics, Biology and Medicine, 1999. 9(1-2): p. 85-91.

132. Sigfridsson, A., et al., In vivo SNR in DENSE MRI; temporal and regional effects of field strength, receiver coil sensitivity and flip angle strategies. Magnetic Resonance Imaging, 2011. 29(2): p. 202-208.

133. Sigfridsson, A., et al., Single-breath-hold multiple-slice DENSE MRI. Magnetic Resonance in Medicine, 2010. 63(5): p. 1411-1414.

134. Cerqueira, M.D., et al., Standardized Myocardial Segmentation and Nomenclature for Tomographic Imaging of the Heart. Circulation, 2002. 105(4): p. 539-542.

135. Kowallick, J.T., et al., Quantification of Left Ventricular Torsion and Diastolic Recoil Using Cardiovascular Magnetic Resonance Myocardial Feature Tracking. PLOS ONE, 2014. 9(10): p. e109164.

136. Hudsmith, L.E., et al., Normal Human Left and Right Ventricular and Left Atrial Dimensions Using Steady State Free Precession Magnetic Resonance Imaging. Journal of Cardiovascular Magnetic Resonance (Taylor \& Francis Ltd), 2005. 7(5): p. 775-782. 
137. Lang, R.M., et al., Recommendations for Chamber Quantification: A Report from the American Society of Echocardiography's Guidelines and Standards Committee and the Chamber Quantification Writing Group, Developed in Conjunction with the European Association of Echocardiography, a Branch of the European Society of Cardiology. Journal of the American Society of Echocardiography, 2005. 18(12): p. 1440-1463.

138. Heiberg, E., et al., Design and validation of Segment-freely available software for cardiovascular image analysis. BMC medical imaging, 2010. 10(1): p. 1.

139. Heiberg, E., et al., Automated Quantification of Myocardial Infarction from MR Images by Accounting for Partial Volume Effects: Animal, Phantom, and Human Study. Radiology, 2008. 246(2): p. 581-588.

140. Mewton, N., et al., Assessment of myocardial fibrosis with cardiovascular magnetic resonance. Journal of the American College of Cardiology, 2011. 57(8): p. 891-903.

141. Dabir, D., et al., Age-gender reference values of native myocardial T1 at $1.5 T$ and $3 T$ : comparison of MOLLI and shMOLLI. Journal of Cardiovascular Magnetic Resonance, 2013. 15(1): p. P91.

142. Lee, J.J., et al., Myocardial T1 and extracellular volume fraction mapping at 3 tesla. Journal of cardiovascular magnetic resonance, 2011. 13(1): p. 75.

143. Kvernby, S., et al., Simultaneous three-dimensional myocardial T1 and T2 mapping in one breath hold with 3D-QALAS. Journal of Cardiovascular Magnetic Resonance, 2014. 16(1): p. 102.

144. Desai, M.Y., et al., The apparent inversion time for optimal delayed enhancement magnetic resonance imaging differs between the right and left ventricles. Journal of Cardiovascular Magnetic Resonance, 2005. 7(2): p. 475-479.

145. Miyagi, H., et al., Quantitative assessment of myocardial strain with displacement encoding with stimulated echoes MRI in patients with coronary artery disease. The International Journal of Cardiovascular Imaging, 2013. 29(8): p. 1779-1786.

146. Goto, Y., et al., Comparison of Displacement Encoding With Stimulated Echoes to Magnetic Resonance Feature Tracking for the Assessment of Myocardial Strain in Patients With Acute Myocardial Infarction. The American Journal of Cardiology, 2017. 119(10): p. 1542-1547.

147. Stokke, T.M., et al., Geometry as a Confounder When Assessing Ventricular Systolic Function: Comparison Between Ejection Fraction and Strain. Journal of the American College of Cardiology, 2017. 70(8): p. 942-954.

148. Kar, J., et al., A Validation of Two-Dimensional In Vivo Regional Strain Computed from Displacement Encoding with Stimulated Echoes (DENSE), in Reference to Tagged Magnetic Resonance Imaging and Studies in Repeatability. Annals of Biomedical Engineering, 2014. 42(3): p. 541-554.

149. Budge, L.P., et al., MR Cine DENSE Dyssynchrony Parameters for the Evaluation of Heart Failure: Comparison With Myocardial Tissue Tagging. JACC: Cardiovascular Imaging, 2012. 5(8): p. 789-797.

150. Schuster, A., et al., Cardiovascular magnetic resonance myocardial feature tracking for quantitative viability assessment in ischemic cardiomyopathy. International Journal of Cardiology, 2011.

151. Hor, K.N., et al., Circumferential strain analysis identifies strata of cardiomyopathy in Duchenne muscular dystrophy. Journal of the American College of Cardiology, 2009. 53(14): p. 1204-1210.

152. Hor, K.N., et al., Comparison of Magnetic Resonance Feature Tracking for Strain Calculation With Harmonic Phase Imaging Analysis. JACC: Cardiovascular Imaging, 2010. 3(2): p. 144-151.

153. Hopp, E., et al., Regional myocardial function after intracoronary bone marrow cell injection in reperfused anterior wall infarction - a cardiovascular magnetic resonance tagging study. Journal of Cardiovascular Magnetic Resonance, 2011. 13(1): p. 1-10. 
154. Donekal, S., et al., Inter-study reproducibility of cardiovascular magnetic resonance tagging. Journal of Cardiovascular Magnetic Resonance, 2013. 15(1): p. 37.

155. Hamlet, S.M., et al., Using a respiratory navigator significantly reduces variability when quantifying left ventricular torsion with cardiovascular magnetic resonance. Journal of Cardiovascular Magnetic Resonance, 2017. 19(1): p. 25.

156. Maret, E.A., Britt-Marie ;Björklund, Per-Gunnar ; Kihlberg, Johan ; Engvall, Jan Analysis of cardiac deformation from MRI: Initial experience of a cine DENSE acquisition at $1.5 T$ compared with feature tracking. European Heart Journal - Cardiovascular Imaging, 2014. 15(suppl_1): p. i12-i33.

157. Bland, J. and D. Altman, Statistical methods for assessing agreement between two methods of clinical measurement. Lancet, 1986. 1: p. 307 - 310.

158. Zaki, R., et al., Statistical methods used to test for agreement of medical instruments measuring continuous variables in method comparison studies: a systematic review. PloS one, 2012. 7(5): p. e37908.

159. Young, A.A., Ventricular Torsion. JACC: Cardiovascular Imaging, 2012.

160. Mangion, K., et al., Comparative prognostic value of myocardial strain derived from DENSE CMR: the British Heart Foundation MR-MI study. The Lancet, 2017. 389: p. S66. 


\section{Papers}

The papers associated with this thesis have been removed for copyright reasons. For more details about these see:

http:// urn.kb.se/ resolve?urn=urn:nbn:se:liu:diva-143028 